Submitted, accepted and published by

Energy Fuels 2015, 29, 6605-6615

\title{
Evaluation of manganese minerals for chemical looping combustion
}

D. Mei,${ }^{\dagger}$ T. Mendiara,${ }^{\dagger}$ A. Abad, ${ }^{* \dagger}$ L. F. de Diego, ${ }^{\dagger}$ F. García-Labiano, ${ }^{\dagger}$ P. Gayán, ${ }^{\dagger}$ J. Adánez, ${ }^{\dagger}$ H. Zhao*

${ }^{\dagger}$ Department of Energy and Environment, Instituto de Carboquímica (ICB-CSIC),

Miguel Luesma Castán 4, Zaragoza 50018, Spain

${ }^{\ddagger}$ State Key Laboratory of Coal Combustion, Huazhong University of Science and Technology, Wuhan 430074, People's Republic of China

\footnotetext{
* Corresponding author. Tel.: +34 976 733977; Fax: +34 976733318.

E-mail address: abad@icb.csic.es (A. Abad)
} 


\section{Abstract}

The use of mineral materials as oxygen carriers for Chemical Looping Combustion (CLC) is an attractive option due to their low cost. This paper reports an experimental study of four manganese minerals as potential oxygen carriers focusing on the behaviour in CLC as well as in Chemical Looping with Oxygen Uncoupling (CLOU). Experiments were carried out in a thermogravimetric apparatus (TGA) and a fluidized-bed reactor. Repeated tests with all the minerals showed no sufficient CLOU properties. Then, they can only be used in CLC applications involving the redox pairs $\mathrm{Mn}_{3} \mathrm{O}_{4} / \mathrm{MnO}$ and $\mathrm{Fe}_{2} \mathrm{O}_{3} / \mathrm{Fe}_{3} \mathrm{O}_{4}$. Oxygen transport capacity and reactivity to the main fuel gases $\left(\mathrm{H}_{2}, \mathrm{CO}\right.$ and $\left.\mathrm{CH}_{4}\right)$ were determined in a TGA with gaseous fuels.

Manganese minerals were also tested during $35-54 \mathrm{~h}$ in a fluidized-bed reactor to evaluate the evolution of reactivity to $\mathrm{H}_{2}, \mathrm{CO}$ and $\mathrm{CH}_{4}$, as well as their attrition rate and mechanical strength. The reactivity of the materials decreased in the first 10 cycles with $\mathrm{CH}_{4}$ and then became quite stable for the rest of the cycles performed with $\mathrm{CH}_{4}, \mathrm{CO}$ and $\mathrm{H}_{2}$. In comparison to previously tested Fe-based minerals, lower reactivity with $\mathrm{CH}_{4}$ was found for the manganese minerals. However, in terms of $\mathrm{CO}$ and $\mathrm{H}_{2}$ combustion, their reactivity was adequately high. During the tests, agglomeration and de-fluidization were never found for any material. Mechanical crushing strength of the particles decreased with cycles, which led to the increase of attrition rate of some materials above acceptable levels. Nevertheless, materials with adequate crushing strength and low attrition were identified. Combining the reactivity 


\author{
and attrition resistance, the manganese mineral MnSA from South Africa can be \\ suggested as a promising material for CLC with coal.
}

Keywords: $\mathrm{CO}_{2}$ capture; Coal; Chemical looping combustion; Manganese minerals;

\author{
Low-cost oxygen carriers
}




\section{Introduction}

The use of fossil fuels as a primary source for energy production cannot be completely substituted in the coming years, while other alternatives, such as renewable energies, become mature ${ }^{1}$. In the process of energy transformation from fossil fuels, the $\mathrm{CO}_{2}$ emission is a crucial issue, due to its impact on the greenhouse effect. In order to mitigate $\mathrm{CO}_{2}$ emissions, clean coal technologies have been developed during the past years. Among these technologies, Chemical Looping Combustion (CLC) emerged as a low-cost technology for $\mathrm{CO}_{2}$ capture ${ }^{2}$. A CLC system is mainly composed by two reactors: air reactor and fuel reactor. An oxygen carrier, normally a metal oxide $\left(\mathrm{MeO}_{\mathrm{x}}\right)$, circulates between the two reactors to provide the oxygen source for fuel $\left(\mathrm{C}_{\mathrm{n}} \mathrm{H}_{2 m}\right)$ combustion, while the mixing of air and fuel is prevented. The oxygen carrier is reduced to $\mathrm{MeO}_{\mathrm{x}-1}$ in the fuel reactor, via reaction $\mathrm{R} 1$, and then re-oxidized to the oxygen-enriched form in the air reactor, via reaction R2. Subsequently, the regenerated oxygen carrier is returned to the fuel reactor allowing the continuous combustion of fuels. Ideally, the gas products from fuel reactor contain only $\mathrm{CO}_{2}$ and $\mathrm{H}_{2} \mathrm{O}$ (reaction $\mathrm{R} 1$ ). Since the separation of $\mathrm{CO}_{2}$ from $\mathrm{H}_{2} \mathrm{O}$ can be accomplished via a simple steam condensation, the CLC process can be considered as a low-cost technology with intrinsic $\mathrm{CO}_{2}$ separation.

Fuel reactor: $\mathrm{C}_{\mathrm{n}} \mathrm{H}_{2 \mathrm{~m}}+(2 \mathrm{n}+\mathrm{m}) \mathrm{MeO}_{\mathrm{x}} \longrightarrow(2 \mathrm{n}+\mathrm{m}) \mathrm{MeO}_{\mathrm{x}-1}+\mathrm{n} \mathrm{CO}_{2}+\mathrm{m} \mathrm{H}_{2} \mathrm{O}$

Air reactor: $\mathrm{MeO}_{\mathrm{x}-1}+1 / 2 \mathrm{O}_{2} \longrightarrow \mathrm{MeO}_{\mathrm{x}}$ 
In the case of using solid fuels in CLC, e.g. coal, reaction R1 between oxygen carrier and fuels becomes extremely slow ${ }^{3}$. Therefore, two approaches were proposed to improve the combustion: in situ Gasification Chemical Looping Combustion $(i \mathrm{G}-\mathrm{CLC})^{4}$ and Chemical Looping with Oxygen Uncoupling (CLOU) ${ }^{5}$. In the $i \mathrm{G}-\mathrm{CLC}$ process, the solid fuel is directly introduced to fuel reactor, where char gasification by $\mathrm{H}_{2} \mathrm{O}$ and/or $\mathrm{CO}_{2}$ and the reaction of the gasification products with oxygen carrier occur simultaneously. Considering the volatiles from the pyrolysis of coal, the main gases to be burnt in $i \mathrm{G}-\mathrm{CLC}$ are $\mathrm{CH}_{4}, \mathrm{CO}$ and $\mathrm{H}_{2}$. In the CLOU process a different mechanism is involved. In this case, the oxygen carrier releases gaseous oxygen for fuel combustion.

One of the concerns both in the $i \mathrm{G}-\mathrm{CLC}$ and CLOU approaches is the losses of oxygen carrier that may be associated to the drainage of the ashes produced during solid fuel combustion which should be compensated with a make-up stream of new oxygen carrier. In order to minimize the operating costs associated to ash drainage, low-cost oxygen carriers are desirable in CLC for solid fuel combustion. In this context, iron-based and manganese-based minerals were considered during last years as promising materials for $\mathrm{CLC}^{6}$. In the case of iron-based minerals, experimental tests in continuous pilot units allowed the identification of several oxygen carriers for the further scale-up of the $i \mathrm{G}-\mathrm{CLC}$ process ${ }^{7-11}$. Among them ilmenite was extensively investigated and was recently considered for the scale-up to $50 \mathrm{~kW}-1 \mathrm{MW}$ for coal combustion $^{8,11,12}$. 
Manganese minerals are also attractive as oxygen carriers for CLC, although they received less attention than Fe-based materials in terms of the number of papers published. Theoretically, $\mathrm{Mn}_{2} \mathrm{O}_{3}$ contained in manganese minerals can release gaseous oxygen in the transformation $\mathrm{Mn}_{2} \mathrm{O}_{3} / \mathrm{Mn}_{3} \mathrm{O}_{4}{ }^{5}$. However, with the presence of $\mathrm{Fe}_{2} \mathrm{O}_{3}$ together with $\mathrm{Mn}_{2} \mathrm{O}_{3}$, the cases become different. A recent thermodynamic calculation suggests that the bixbyte in Fe-Mn-O system is responsible for the release of gaseous oxygen ${ }^{13}$. However, this component cannot be regenerated by air at temperatures higher than $900^{\circ} \mathrm{C}^{13}$. Therefore, in practical conditions low CLOU effect was observed for manganese minerals ${ }^{14}$. Moreover, the CLOU effect decreased with the number of cycles which can be attributed to the presence of $\mathrm{Mn}_{3} \mathrm{O}_{4}$ instead of $\mathrm{Mn}_{2} \mathrm{O}_{3}$ in the manganese material after several cycles ${ }^{15}$. These findings imply that $\mathrm{Mn}_{2} \mathrm{O}_{3}$ cannot be regenerated at practical temperatures and therefore, manganese minerals seemed to be more suitable for gas fuelled CLC or $i \mathrm{G}-\mathrm{CLC}$ for solid fuels, based on the redox pair $\mathrm{Mn}_{3} \mathrm{O}_{4} / \mathrm{MnO}$.

Some investigations were carried out using manganese minerals for $\mathrm{CH}_{4}, \mathrm{H}_{2}$ or syngas combustion in a thermogravimetric apparatus (TGA) or in a fluidized-bed reactor $^{15-19}$. Results showed a high reactivity of manganese materials to $\mathrm{H}_{2}$ and syngas $^{17,18}$, however, poor mechanical stability, poor fluidizing properties and even agglomeration were also encountered ${ }^{18}$. A recent investigation with a Brazilian manganese mineral in the combustion of $\mathrm{CH}_{4}$ showed high conversion of $\mathrm{CH}_{4}$ and 
good fluidization ${ }^{15}$. Nevertheless, the reactivity of this mineral with $\mathrm{CO}$ and $\mathrm{H}_{2}$, the main gases involved in char gasification, could not be determined ${ }^{15}$.

The Brazilian manganese mineral was further used in experiments in a $10 \mathrm{~kW}_{\text {th }}$ CLC unit burning coal ${ }^{20}$. High combustion efficiencies and $\mathrm{CO}_{2}$ captures were obtained. These good results were attributed to an improvement in the rates of char gasification in the presence of manganese minerals up to five times when compared to similar experiments using ilmenite ${ }^{14,15,21}$. Despite this, high attrition rate and low mechanical strength were observed for the Brazilian manganese mineral during the operation in the continuous unit ${ }^{20}$. The high attrition rate of the manganese minerals might be the most important problem to overcome for the long-term use in CLC. In this sense, more research is necessary to develop manganese minerals with high reactivity and low attrition rate for the applications to CLC.

Thus, the objective of the present study is to contribute to the development of manganese minerals as potential oxygen carriers for CLC. With this aim, different manganese minerals were tested in experiments both using TGA and batch fluidized-bed reactor in order to analyze their reactivity with the main gases presented in CLC. Mechanical properties, including attrition, crushing strength and agglomeration behaviour were also examined. 


\section{Experimental}

\subsection{Manganese minerals}

Four different manganese minerals were tested in this work for the possible use as oxygen carriers in CLC. In order to identify them throughout this paper, they were denoted as MnSA, MnGBHNE, MnGBMPB and MnBR depending on their origin countries: South Africa (SA), Gabon (GB) and Brazil (BR), respectively. Furthermore, in order to identify the two minerals from Gabon throughout this work, the supplier names were abbreviated in the denominations, i.e. HNE and MPB. The MnSA and MnGBHNE manganese minerals, respectively from South Africa and Gabon, were both supplied by Hidro Nitro Española S.A. The second sample from Gabon, MnGBMPB, was commercially distributed manganese mineral provided by Mario Pilato Blatt S.A. Finally, the MnBR from Brazil is a similar material to that used elsewhere ${ }^{14,15}$, which was supplied by Mineração Buritirama. Once received, they were dried at room temperature for $72 \mathrm{~h}$ to remove the humidity and then crushed and sieved to particles in the range of 100-300 $\mu \mathrm{m}$. According to previous works ${ }^{3,7,9,10,12}$, this particle size interval was considered as desirable size to get better fluidization and reaction behaviours in fluidized bed reactors. More indeed, according to a recent experimental investigation ${ }^{22}$ particle within 100-300 $\mu \mathrm{m}$ showed satisfactory fluidization behaviour in loop-seal involved in CLC system. In addition, particle size 
in this range does not affect to the reactivity of materials. Prior to the tests, all the samples were calcined in air at $800^{\circ} \mathrm{C}$ for $2 \mathrm{~h}$ to ensure the complete oxidation.

The chemical composition of the materials was determined by inductively coupled plasma atomic emission spectroscopy (ICP-AES) with a Jobin Ybon 2000 apparatus. Crystalline chemical species were identified by powder X-ray diffraction (XRD) patterns acquired in an X-ray diffractometer Bruker AXS D8ADVANCE using $\mathrm{Ni}$-filtered $\mathrm{Cu} \mathrm{K} \alpha$ radiation equipped with a graphite monochromator. The force needed to fracture a particle was determined using a Shimpo FGN-5X apparatus. The crushing strength of each material was taken as the average value of at least 20 measurements. The Air Jet Attrition Index (AJI) was calculated as the percentage of fines after a five hours test in a Ma. Tec. ATTRI-AS air jet attrition tester, following the ASTM D5757-00 standard ${ }^{23,24}$. The porosity and pore size of the particles were measured by Hg intrusion in a Quantachrome PoreMaster 33. The specific surface area of the particles was determined by the Brunauer-Emmett-Teller (BET) method through adsorption/desorption of nitrogen at $77 \mathrm{~K}$ in a Micromeritics ASAP-2020 instrument. Particle size distribution (PSD) of the materials was determined with a LS 13320 of Beckman Coulter equipment. Finally, microstructure of the materials was observed in an ISI DS-130 type scanning electron microscope (SEM). The main chemical and physical properties of all the manganese minerals mentioned are presented in Table 1 and 2. 
In Table 1 , XRD results showed that the main crystalline phases are $\mathrm{Mn}_{2} \mathrm{O}_{3}, \mathrm{Mn}_{3} \mathrm{O}_{4}$, $\mathrm{Fe}_{2} \mathrm{O}_{3}$ and the inactive $\mathrm{SiO}_{2}$ in the calcined particles, depending on the materials. However, the $\mathrm{Mn}_{2} \mathrm{O}_{3}$ cannot be regenerated by air after reduction. In this case, the active composition of the manganese minerals in redox cycles was determined in TGA tests following the procedure detailed in Supporting Information. $\mathrm{Mn}_{3} \mathrm{O}_{4}$ and $\mathrm{Fe}_{2} \mathrm{O}_{3}$ were considered as the stable phases as it is shown in Table 2. The oxygen transport capacity, $R_{\mathrm{OC}}$, was calculated through the following equation.

$$
R_{\mathrm{OC}}=\frac{m_{\mathrm{o}}-m_{\mathrm{r}}}{m_{\mathrm{o}}}
$$

where $m_{\mathrm{o}}$ and $m_{\mathrm{r}}$ are the registered masses of fully oxidized and reduced manganese mineral in TGA tests, respectively. Crushing strength of these calcined materials varied from 1.0 to $4.6 \mathrm{~N}$ (Table 2) which is adequante for the utilization in fluidization systems based on a previous study ${ }^{25}$.

\subsection{Experimental setup and procedure}

\subsubsection{Thermogravimetric apparatus (TGA)}

The reactivity of the manganese minerals was first analyzed in a CI Electronics type TGA at atmospheric pressure. The TGA was well defined to explore the reactivity and the available oxygen stored in the materials. Detailed description of the TGA apparatus can be found elsewhere ${ }^{26}$. In all the experiments, around $50 \mathrm{mg}$ of the particles were loaded in a platinum basket. Mn-based materials are potentially valid 
for CLC and CLOU applications, therefore, the reactivity with gaseous fuels and the oxygen uncoupling capability were tested, respectively.

To evaluate the reactivity with gaseous fuels, the manganese materials were exposed to alternating reduction and oxidation cycles at $950^{\circ} \mathrm{C}$. During the reductions, $5 \% \mathrm{H}_{2}$ $+40 \% \mathrm{H}_{2} \mathrm{O}, 15 \% \mathrm{CO}+20 \% \mathrm{CO}_{2}$ and $15 \% \mathrm{CH}_{4}+20 \% \mathrm{H}_{2} \mathrm{O}$, balanced by $\mathrm{N}_{2}$ respectively, were used as reducing mixtures. $\mathrm{H}_{2} \mathrm{O}$ mixed with $\mathrm{CH}_{4}$ and $\mathrm{CO}_{2}$ mixed with $\mathrm{CO}$ were used to avoid possible carbon formation and to slow Boudouard reaction, respectively. When steam was desired in the reacting mixture, the gases were bubbled through a saturator containing water at the saturation temperatures 60 and $75^{\circ} \mathrm{C}$ to reach the steam concentrations 20 and $40 \%$, respectively. For the oxidations, air was used after the purge to regenerate the previously reduced materials.

The concentration of $15 \%$ for $\mathrm{CO}$ and $\mathrm{CH}_{4}$ was used to facilitate the reactivity comparison between different materials following the methodology proposed by Johansson et al. ${ }^{25}$. However, the $\mathrm{H}_{2}$ concentration was $5 \%$ in this work to limit the reduction of iron oxide to $\mathrm{Fe}_{3} \mathrm{O}_{4}$ by using a low $\mathrm{H}_{2}$ concentration joined to a high $\mathrm{H}_{2} \mathrm{O}$ concentration $^{27}$. Later, the reactivity was normalized to a concentration of $15 \%$ following the same methodology. An improved methodology to compare reactivity of different materials was proposed by Abad et al. ${ }^{28}$, but it requires the knowledge of the reaction order. 
To evaluate the oxygen uncoupling capability, temperature programmed decomposition and oxidation (TPD and TPO) as well as cycles at $800^{\circ} \mathrm{C}$ were performed to evaluate the oxygen release and uptake. The TPD tests were carried out in $\mathrm{N}_{2}$ with increasing temperature from room level to $950^{\circ} \mathrm{C}$, at $20^{\circ} \mathrm{C} / \mathrm{min}$, whereas the TPO was performed in air and decreasing the temperature from $950^{\circ} \mathrm{C}$ to the room level at $7^{\circ} \mathrm{C} / \mathrm{min}$. The isothermal cycles were performed at $800^{\circ} \mathrm{C}$ in alternating $\mathrm{N}_{2}$ and air. During the cycles, $800^{\circ} \mathrm{C}$ was selected for oxidation according to the thermodynamic equilibrium of the $\mathrm{Mn}_{2} \mathrm{O}_{3} / \mathrm{Mn}_{3} \mathrm{O}_{4}$ system to allow the necessary oxidation to $\mathrm{Mn}_{2} \mathrm{O}_{3}{ }^{5}$.

\subsubsection{Batch fluidized-bed reactor}

Experiments in fluidized-bed reactor allow the investigation of the gas product distribution during reactions, the attrition behavior of the manganese minerals as well as the possible agglomeration phenomena.

Figure 1 presents the scheme of the batch fluidized-bed reactor. A detailed description can be found elsewhere ${ }^{29-31}$. For each mineral, $300 \mathrm{~g}$ of manganese mineral were loaded in the reactor. All the tests were performed at $950^{\circ} \mathrm{C}$. After the temperature was reached, the material was exposed to alternating reducing and oxidizing cycles. Gases for the reduction, purge and oxidation were supplied and introduced into the reactor through a 4-way valve upstream the reactor, to simulate a CLC process. The 
flows of these gases were controlled separately by mass flow meters, except the steam flow. In the case of steam, a peristaltic pump supplied the necessary water flow, which was heated to produce steam by a resistance heater before entering the reactor. For comparison purposes, the reducing gas flows and concentrations were chosen to have the same oxygen consumption. The reducing mixtures used in the experiments were $25 \% \mathrm{CH}_{4}+10 \% \mathrm{H}_{2} \mathrm{O}, 50 \% \mathrm{CO}+20 \% \mathrm{CO}_{2}$ and $50 \% \mathrm{H}_{2}+20 \% \mathrm{H}_{2} \mathrm{O}$, respectively, balanced by $\mathrm{N}_{2}$. In all the cases, the gas velocity was 6-16 times the minimum fluidization velocity. Oxidations of the reduced samples were carried out after a period of purge in nitrogen. Diluted air containing $10 \% \mathrm{O}_{2}$ was used to avoid high temperature increase during oxidation. Depending on the materials used, the reduction and oxidation of each material took 3-4 and 10min, respectively. Because of the potential use of manganese minerals for CLOU application, the bed was purged with $\mathrm{N}_{2}$ for 5 min after oxidation to observe the possible oxygen release. Additionally, $\mathrm{N}_{2}$ and air were respectively used during reactor heating and cooling to observe the possible oxygen release and uptake at different temperatures. Two identical hot filters were located downstream the reactor, which were used to sequentially retain the solids elutriated during the tests. The filter was composed of a steel tube, a ceramic fiber and some glass wools to guarantee the complete retention of fines at the outlet of reactor. In order to obtain the attrition rates of the particles, the amount of fines in the filters was recorded regularly. The differential pressure drop between the bottom and top of the reactor was measured to detect possible agglomeration problems of the materials. All the pipes and the filters were heated to avoid steam condensation in the 
pipe lines. The gas product stream was sent to several gas analyzers to determine the gas concentrations. The concentrations of $\mathrm{CH}_{4}, \mathrm{CO}, \mathrm{CO}_{2}$, and $\mathrm{H}_{2} \mathrm{O}$ were measured by non-dispersive infrared (NDIR) analyzer, and the concentration of $\mathrm{H}_{2}$ by a thermal conductivity detector (TCD). Oxygen concentration was measured using a paramagnetic analyzer.

\subsection{Data evaluation}

\subsubsection{TGA data}

The solid conversion for the reduction, $X_{\mathrm{r}}$, and oxidation, $X_{\mathrm{o}}$, of the manganese minerals were calculated from the mass variations registered in TGA.

Reduction:

$$
X_{\mathrm{r}}=\frac{m_{\mathrm{o}}-m}{R_{\mathrm{OC}} m_{\mathrm{o}}}
$$

Oxidation:

$$
X_{\mathrm{o}}=\frac{m-m_{\mathrm{r}}}{R_{\mathrm{OC}} m_{\mathrm{o}}}
$$

where $m$ is the instantaneous mass of the sample.

Following the methodology provided by Johansson et al. ${ }^{25}$, a normalized rate index,

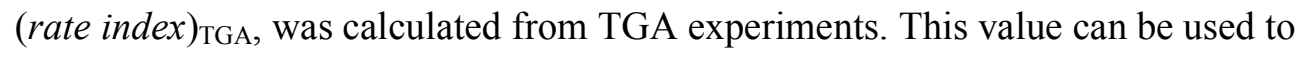


evaluate the reactivity of the oxygen carriers with different gases, e.g. $\mathrm{H}_{2}, \mathrm{CO}, \mathrm{CH}_{4}$ and $\mathrm{O}_{2}^{25}$.

$(\text { rate index })_{\mathrm{TGA}}=100 \cdot 60 \cdot R_{\mathrm{OC}} \cdot\left(\frac{d X_{i}}{d t}\right)_{\text {norm }}$

where the constants 100 and 60 were used to get the unit $\% / \mathrm{min}$, and the normalized reactivity $\left(d X_{i} / d t\right)_{\text {norm }}$ is calculated as eq. 5 following the first-order reaction assumption made by Johansson et al. ${ }^{25}$.

$\left(\frac{d X_{i}}{d t}\right)_{\text {norm }}=\frac{p_{\text {ref }}}{p_{\mathrm{TGA}}} \cdot\left(\frac{d X_{i}}{d t}\right)_{\text {exp }}$ where $p_{\text {ref }}$ is fixed to $0.15 \mathrm{~atm}$ for reduction, viz. when $X_{i}=X_{\mathrm{r}}$, and to $0.1 \mathrm{~atm}$ for oxidation, viz. when $X_{i}=X_{\mathrm{o}}$, respectively ${ }^{25} \cdot p_{\mathrm{TGA}}$ is the partial pressure of the gas used in the TGA experiments. For the calculation of (rate index $)_{\mathrm{TGA}}$ during the oxidation process, the oxidation after the reduction with $5 \% \mathrm{H}_{2}+40 \% \mathrm{H}_{2} \mathrm{O}$ was considered. In this way reduction of iron oxide to $\mathrm{FeO}$ was avoided, and the oxidation of $\mathrm{Fe}_{3} \mathrm{O}_{4}$ to $\mathrm{Fe}_{2} \mathrm{O}_{3}$ was guaranteed.

\subsubsection{Fluidized-bed reactor data}

From the gas product distribution obtained in the fluidized-bed reactor, it is possible to calculate the molar rate of oxygen transferred from the manganese minerals to the fuels as a function of time, $r_{\mathrm{O}}(t)$, according to an oxygen balance.

Reduction:

$$
r_{\mathrm{O}}(t)=\left(\chi_{\mathrm{CO}}+2 \chi_{\mathrm{CO}_{2}}+\chi_{\mathrm{H}_{2} \mathrm{O}}\right)_{\text {out }} \cdot F_{\text {out }}-\left(\chi_{\mathrm{CO}}+2 \chi_{\mathrm{CO}_{2}}+\chi_{\mathrm{H}_{2} \mathrm{O}}\right)_{\text {in }} \cdot F_{\text {in }}
$$


Oxidation:

$r_{\mathrm{O}}(t)=\left(2 \chi_{\mathrm{O}_{2}}\right)_{\text {in }} \cdot F_{\text {in }}-\left(2 \chi_{\mathrm{O}_{2}}\right)_{\text {out }} \cdot F_{\text {out }}$

where $F_{\text {in }}$ and $F_{\text {out }}$ are respectively the inlet and outlet molar flows of gases from the reactor and $\chi_{i}$ is the molar fraction of the gas $i\left(i=\mathrm{CO}, \mathrm{CO}_{2}, \mathrm{H}_{2} \mathrm{O}\right.$ or $\left.\mathrm{O}_{2}\right)$ at the reactor inlet, $\left(\chi_{i}\right)_{\text {in }}$, or the reactor outlet, $\left(\chi_{i}\right)_{\text {out }}$.

The evolution of the conversion of solids during reduction and oxidation in the fluidized-bed reactor was evaluated by calculating the oxygen conversion as a function of time, $X_{\mathrm{o}}$. The value of $X_{\mathrm{o}}$ was calculated by the integration of $r_{\mathrm{O}}(t)$ from the beginning of reaction ( $t=t_{0, r}$ for reduction or $t=t_{0, o}$ for oxidation) to a time $t$, see eq. 8 and eq. 9.

Reduction:

$$
X_{\mathrm{o}}(t)=1-\frac{M_{\mathrm{O}}}{R_{O C} m_{\mathrm{o}}} \int_{\mathrm{t}_{0, \mathrm{r}}}^{t-\mathrm{t}_{0, \mathrm{r}}} r_{\mathrm{O}}(t) \cdot d t
$$

Oxidation:

$$
X_{\mathrm{o}}(t)=X_{\mathrm{o}, \text { redf }}+\frac{M_{\mathrm{O}}}{R_{\mathrm{OC}} m_{\mathrm{o}}} \int_{\mathrm{t}_{0, \mathrm{o}}}^{t-\mathrm{t}_{0, \mathrm{o}}} r_{\mathrm{O}}(t) \cdot d t
$$

where $M_{\mathrm{O}}$ is the molar weight of oxygen, $m_{\mathrm{o}}$ is the mass of fully oxidized solids in the reactor and $X_{\mathrm{o} \text {,redf }}$ is the oxygen conversion at the end of the reduction step.

The reaction rate in batch experiments can be obtained as the following equation.

$$
\left(-\frac{d X_{\mathrm{o}}}{d t}\right)_{\exp }=\frac{M_{\mathrm{O}}}{R_{\mathrm{OC}} m_{\mathrm{o}}} \cdot r_{\mathrm{O}}(t)
$$


The rate index in the fluidized-bed tests, $(\text { rate index })_{\mathrm{FB}}$, was also calculated. This parameter was used to evaluate and compare the reactivity of different materials in fluidized-bed reactor. The (rate index $)_{\mathrm{FB}}$ can be obtained through eq. 11 .

$$
(\text { rate index })_{\mathrm{FB}}=100 \cdot 60 \cdot R_{\mathrm{OC}} \cdot\left(-\frac{d X_{\mathrm{o}}}{d t}\right)_{\mathrm{norm}}
$$

being $\left(-d X_{\mathrm{o}} / d t\right)_{\text {norm }}$ the normalized reaction rate calculated through eq. 12 assuming first-order of reactions in all the cases. To facilitate the comparison, experimental data at $X_{\mathrm{o}}=0.8$ was used.

$$
\left(-\frac{d X_{\mathrm{o}}}{d t}\right)_{\text {norm }}=\left(-\frac{d X_{\mathrm{o}}}{d t}\right)_{\exp } \cdot \frac{p_{\text {ref }}}{p_{\mathrm{m}}}
$$

In eq. $12 p_{\text {ref }}$ refers to a reference partial pressure $(0.15 \mathrm{~atm})$, which would approximately corresponds to a full conversion of the gas, $p_{\mathrm{m}}$ refers to the average partial pressure of the gaseous fuel in the reactor being calculated by eq. 13 through an integration process. Here assumption of first-order reaction was made ${ }^{28}$.

$$
p_{\mathrm{m}}=\frac{\left(p_{\text {in }}-p_{\text {out }}\right) \cdot p_{\text {in }}}{\left(p_{\text {out }}-p_{\text {in }}\right) \cdot \varepsilon_{\mathrm{g}}+\left(p_{\text {in }}+\varepsilon_{\mathrm{g}} \cdot p_{\text {out }}\right) \cdot\left(1+\varepsilon_{\mathrm{g}}\right) \cdot \ln \left(\frac{p_{\text {in }}+\varepsilon_{\mathrm{g}} \cdot p_{\text {out }}}{\left(1+\varepsilon_{\mathrm{g}}\right) \cdot p_{\text {out }}}\right)}
$$

where $p_{\text {in }}$ and $p_{\text {out }}$ represent the partial pressures of the gaseous fuel at the inlet and outlet of the reactor, respectively, and $\varepsilon_{\mathrm{g}}$ is the expansion factor, i.e. $\varepsilon_{\mathrm{g}}=0$ for $\mathrm{CO}$ and $\mathrm{H}_{2}$ and $\varepsilon_{\mathrm{g}}=0.5$ for reduction with $25 \% \mathrm{CH}_{4}$. 


\section{Results and Discussion}

\subsection{Determination of the redox active compounds}

First, the investigation of the CLOU effect as well as the redox active compounds of the four manganese minerals was carried out. Regarding the CLOU behavior, four types of tests were performed to detect the possible cyclic oxygen release and uptake for the $\mathrm{Mn}_{2} \mathrm{O}_{3} / \mathrm{Mn}_{3} \mathrm{O}_{4}$ redox system. In the TGA, temperature programmed decomposition and oxidation tests (TPD-TPO) together with cycles in $\mathrm{N}_{2}$ and air at a fixed temperature were performed. In the fluidized-bed reactor, heating in $\mathrm{N}_{2}$ and cooling in air together with long-term purges between cycles were done.

During TPD tests in nitrogen in TGA, mass losses were observed for all the uncalcined materials. However, during the following TPO in air no mass gains were seen, suggesting that re-oxidation of these materials cannot occur at any temperature in air atmosphere. Besides these tests, successive cycles at $800^{\circ} \mathrm{C}$ in alternating air and $\mathrm{N}_{2}$ atmospheres in TGA showed some mass losses during the first exposure in $\mathrm{N}_{2}$, which corresponded to $0.3 \mathrm{wt} . \%, 2.0 \mathrm{wt} . \%, 1.3 \mathrm{wt} . \%$ and $0.8 \mathrm{wt} . \%$ of the mass of MnSA, MnGBHNE, MnGBMPB and MnBR, respectively. These weight losses could be related to the decomposition of $\mathrm{Mn}_{2} \mathrm{O}_{3}$, because the calcined minerals may initially contain $\mathrm{Mn}_{2} \mathrm{O}_{3}$ phase according to the XRD results in Table 1. However, after the first cycle, the regeneration of $\mathrm{Mn}_{2} \mathrm{O}_{3}$ by air hardly proceeded, which led to a decrease in 
the mass losses observed in the following cycles in $\mathrm{N}_{2}$. The mass losses of the $3^{\text {rd }}$ cycle corresponded to $0.2 \mathrm{wt} . \%, 0.1 \mathrm{wt} . \%, 0.1 \mathrm{wt} . \%$ and $0.1 \mathrm{wt} . \%$ for MnSA, MnGBHNE, MnGBMPB and MnBR, respectively. The oxygen release rate in this cycle is in the range $10^{-6} \mathrm{kgO} /(\mathrm{s} \cdot \mathrm{kgOC})$, which corresponds to $1-3 \%$ of the decomposition rates calculated for other CLOU oxygen carriers such as $\mathrm{CuO} / \mathrm{CuAl}_{2} \mathrm{O}_{4}{ }^{32}$ and $\mathrm{CuO} / \mathrm{MgAl}_{2} \mathrm{O}_{4}{ }^{33}$. This comparison suggests that the rate of oxygen release from the manganese minerals tested in this work can be considered negligible.

The importance of the CLOU effect was also checked during the tests in the fluidized-bed reactor. The first heating of the sample introduced in the fluidized-bed-reactor was done using $\mathrm{N}_{2}$, in order to observe the oxygen release. The maximum oxygen concentration obtained with the materials here tested was $2.8 \%$. However, in the subsequent long-term purges in nitrogen between reduction and oxidation of the samples, oxygen release was never found. Moreover, the fluidized-bed was always cooled in air and under these conditions no oxygen uptake was noticed in any case. Therefore, the following irreversible reaction, reaction R3, can be proposed for the transformation between $\mathrm{Mn}_{2} \mathrm{O}_{3}$ and $\mathrm{Mn}_{3} \mathrm{O}_{4}$ in $\mathrm{N}_{2}$ and air cycles for all the manganese minerals.

$6 \mathrm{Mn}_{2} \mathrm{O}_{3} \nleftarrow \rightarrow 4 \mathrm{Mn}_{3} \mathrm{O}_{4}+\mathrm{O}_{2}(\mathrm{~g})$ 
The results from TGA and the fluidized-bed tests suggested that the CLOU effect in the manganese minerals tested in this work is not significant, because of the impossibility of $\mathrm{Mn}_{3} \mathrm{O}_{4}$ regeneration to $\mathrm{Mn}_{2} \mathrm{O}_{3}$ under practical operating conditions. Therefore, $\mathrm{Mn}_{3} \mathrm{O}_{4} / \mathrm{MnO}$ as well as $\mathrm{Fe}_{2} \mathrm{O}_{3} / \mathrm{Fe}_{3} \mathrm{O}_{4}$ systems were considered as the redox active pairs throughout this work. The oxygen transport capacity $R_{\mathrm{OC}}$ for these manganese minerals was determined by TGA tests considering the reductions from $\mathrm{Mn}_{3} \mathrm{O}_{4}$ to $\mathrm{MnO}$ and from $\mathrm{Fe}_{2} \mathrm{O}_{3}$ to $\mathrm{Fe}_{3} \mathrm{O}_{4}$ as detailed in Supporting Information. As seen in Table 2, the values of $R_{\mathrm{OC}}$ fall into the range of $4.7-5.8 \mathrm{wt} . \%$, which are high enough for CLC applications ${ }^{28}$.

\subsection{Reactivity of the calcined materials in TGA}

Figure 2 shows the solid conversion as a function of time for the different manganese minerals. At $950^{\circ} \mathrm{C}$ rapid conversion of the manganese minerals was observed. Using $\mathrm{CH}_{4}, \mathrm{CO}$ and $\mathrm{H}_{2}$, complete conversion of the MnSA, MnGBHNE, MnGBMPB and MnBR samples were observed in less than 90 s. In the case of oxidation, rapid regeneration of the materials was also observed with reaction time less than $40 \mathrm{~s}$ (not shown in Figure 2).

The (rate index) $)_{\mathrm{TGA}}$ was calculated in order to compare the reactivity of these manganese minerals to that corresponding to other low-cost materials. Table 3 summarized the (rate index $)_{\mathrm{TGA}}$ for the calcined and used manganese minerals in this 
work. Results corresponding to a previously tested Mn ore ${ }^{17}, \mathrm{Fe}-\mathrm{Mn}$ based materials ${ }^{19}$ and some Fe-based materials ${ }^{34}$ were also included in Table 3. Compared to the results corresponding to the $\mathrm{Mn}$ ore ${ }^{17}$, the reactivity of the calcined MnSA is slightly lower in the reaction with $\mathrm{CH}_{4}$ and $\mathrm{H}_{2}$. However, higher or similar reactivity to that of the $\mathrm{Mn}$ ore was observed for the combustion of $\mathrm{CH}_{4}$ and $\mathrm{H}_{2}$ for the calcined MnGBHNE, MnGBMPB and MnBR samples ${ }^{17}$. In comparison to the recently studied Fe-Mn based materials, SINAI-A and GUIZHOU ${ }^{19}$, available results shows that higher reactivity of our manganese minerals than the Fe-Mn based materials in terms of $\mathrm{CH}_{4}$ and $\mathrm{H}_{2}$ combustion. It is important to highlight that the calcined manganese minerals exhibited higher reactivity to $\mathrm{CO}, \mathrm{H}_{2}$ and $\mathrm{CH}_{4}$ than ilmenite, a bauxite waste and a Fe-ore (hematite) ${ }^{34}$. The reactivity to oxygen was also higher, except for the case of ilmenite. All the Fe-based materials have been successfully tested in continuous CLC units obtaining high carbon captures and combustion efficiencies ${ }^{7,9,10,35}$. This fact could encourage the use of the manganese minerals here tested as oxygen carriers in $i \mathrm{G}-\mathrm{CLC}$ process, as they could even improve the conversion of the $\mathrm{H}_{2}$ and $\mathrm{CO}$ generated during char gasification and lower the value of oxygen demand in the continuous CLC operation. 


\subsection{Reactivity in the fluidized-bed reactor}

\subsubsection{Gas concentration distribution}

The experiments in the fluidized-bed reactor allowed knowing the distribution of gas products during fuel combustion. As an example, Figure 3 depicted stable cycles for the combustion at $950^{\circ} \mathrm{C}$ of $\mathrm{CH}_{4}, \mathrm{CO}$ and $\mathrm{H}_{2}$ with $\mathrm{MnSA}$. The wet-basis concentrations of all the gases in Figure 3 were corrected following a deconvolution method $^{36}$, considering the residence time distribution in the system ${ }^{37}$. In the combustion of $\mathrm{CH}_{4}$, the main reaction products were $\mathrm{CO}_{2}$ and $\mathrm{H}_{2} \mathrm{O}$, although low amounts of $\mathrm{CO}$ and $\mathrm{H}_{2}$ were also detected. During the reduction period methane was not completely converted to $\mathrm{CO}_{2}$ (only around $50 \%$ ). The solid conversion $X_{\mathrm{O}}(t)$ during reduction decreased to a value of approximately 0.6 . After the purge with $\mathrm{N}_{2}$, the MnSA material was regenerated using $10 \% \mathrm{O}_{2}$. During the first 4 min after feeding oxygen, all the oxygen supplied was consumed. At the end of oxidation, the initial oxygen concentration was recovered and full regeneration of the manganese mineral was reached.

Shorter reducing times were used in the reaction of $\mathrm{MnSA}$ with $\mathrm{CO}$ and $\mathrm{H}_{2}$ although higher degrees of reduction were observed, which was related to the reactivity and concentration of the fuels. Thus, the lower reactivity and lower concentration of $\mathrm{CH}_{4}$ 
resulted in lower degree of solid conversion than using $\mathrm{CO}$ or $\mathrm{H}_{2}$ as fuel. Obviously, the more reduction the longer period was required for re-oxidation.

In the case of the other manganese minerals, i.e. MnGBHNE, MnGBMPB and MnBR, similar behaviors to that showed in Figure 3 were observed for $\mathrm{CH}_{4}, \mathrm{CO}$ and $\mathrm{H}_{2}$ combustion. The unconverted $\mathrm{CH}_{4}, \mathrm{CO}$ and $\mathrm{H}_{2}$ that could be observed in the experiments might be attributable to two factors, i.e. the bubbling effect and the amount of manganese mineral introduced into the reactor. If more bed material was fed, complete conversion of the gases would be reached. However, incomplete gas conversion was desired in these experiments in order to calculate the wet-basis average concentrations of fuels via eq. 13 .

In total, $35 \mathrm{~h}$ of operation for MnSA and MnBR, and 54h for MnGBHNE and MnGBMPB were registered corresponding to $40-58$ cycles in the batch reactor. It should be mentioned that in all the cycles, satisfactory fluidization was kept and no agglomeration was found, even when a high degree of solid conversion was reached.

\subsubsection{Evolution of (rate index) $F B$ with cycles}

Stable reactivity of oxygen carriers is desirable for large-scale CLC plants; thereby it is necessary to examine the stability of these materials during cycles. The evolution of reactivity of the four manganese minerals as a function of cycle number is shown in 
Figure 4 where the (rate index $)_{\mathrm{FB}}$ calculated according to eq. 11 was included for evaluation purpose.

In the first tests with methane shown in Figure 4, it can be observed that the values of (rate index $)_{\mathrm{FB}}$ decreased until the $10^{\text {th }}$ cycle and then remained stable. MnGBMPB and MnBR manganese minerals showed similar reactivity with $\mathrm{CH}_{4}$, which was slightly higher than the other samples. The stable values of $(\text { rate index })_{\mathrm{FB}}$ were $\sim 0.4-0.6 \% / \mathrm{min}$ for all the manganese minerals during $\mathrm{CH}_{4}$ combustion. These values

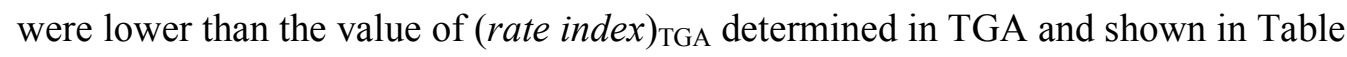
3, although all rate index were normalized to the same gas concentration, i.e. 15 vol.\%. This fact can be attributed to the bubbling effects in fluidized-bed where some reacting gases inside the bubbles caused by fluidization have to diffuse to the emulsion, slowing their reactions with oxygen carrier particles ${ }^{38}$. After 20 cycles with $\mathrm{CH}_{4}$, the materials were subjected to cycles with $\mathrm{CO}$ and $\mathrm{H}_{2}$. The (rate index $)_{\mathrm{FB}}$ for all the materials was quite stable during the 20 cycles with $\mathrm{CO}$ and $\mathrm{H}_{2}$, which indicated that after the cycles with $\mathrm{CH}_{4}$ the manganese minerals had reached stable reactivity. During CO combustion, the highest (rate index) FB $_{\mathrm{Fas}}$ observed for MnSA (around $1 \% / \mathrm{min}$ ), which was $1.5-2.5$ times that of the other samples. This finding is in accordance with the reactivity observed in TGA in the tests with used materials (Table 3). The highest rate index for gaseous fuel combustion was obtained in the experiments with $\mathrm{H}_{2}$ combustion. The stable values of (rate index $)_{\mathrm{FB}}$ during the cycles with $\mathrm{H}_{2}$ were around $1.5-2 \% / \mathrm{min}$. 
Subsequently, the stable values of (rate index $)_{\mathrm{FB}}$ were used to compare with the available data in the literature, see horizontal lines in Figure 4. In a previous work, ilmenite was tested in the same batch reactor and gaseous fuels as this work ${ }^{29}$. In this case, a gain in the reactivity was observed with the number of redox cycles. Stable values of (rate index $)_{\mathrm{FB}}$ after the ilmenite activation step were here considered. The temperature used in these ilmenite tests was $900^{\circ} \mathrm{C}$, which was different to that used in the present work, $950^{\circ} \mathrm{C}$. Nevertheless, the improvement of reaction rate due to temperature increase can be calculated. According to Abad et al. ${ }^{39}, 50 \%$ increment of reduction rate for activated ilmenite was attained by changing the temperature from 900 to $950{ }^{\circ} \mathrm{C}$. Thus, in order to compare the reactivity with manganese minerals this $50 \%$ increment was used in the present work for the same activated ilmenite. The (rate index $)_{\mathrm{FB}}$ calculated in the present work suggest that the reactivity of the manganese minerals was similar to or even lower than that found for ilmenite with $\mathrm{CH}_{4}$. In addition, the reactivity of manganese minerals with $\mathrm{CO}$ and $\mathrm{H}_{2}$ was higher than that of ilmenite. Figure 4 also compares the results from manganese minerals to those obtained in the same batch reactor by Mendiara et al. ${ }^{30}$ with a bauxite waste which was later successfully used in a continuous unit ${ }^{9}$. In the case of $\mathrm{CH}_{4}$ combustion, the rate index at $950^{\circ} \mathrm{C}$ for bauxite waste was $1.1 \% / \mathrm{min}$, which is higher than that corresponding to the manganese minerals in this work. For $\mathrm{H}_{2}$ and $\mathrm{CO}$ combustion, the rate index values for bauxite waste were not calculated due to the complete combustion of these gases ${ }^{30}$. 
As a conclusion, it can be said that the reactivity of the four manganese minerals decreased during the first 10 cycles using $\mathrm{CH}_{4}$. Afterwards, quite stable reactivity can be achieved. The stable rate index for the manganese minerals during $\mathrm{CH}_{4}$ combustion was lower than that obtained under similar conditions with ilmenite ${ }^{29,39}$ and a bauxite waste ${ }^{30}$. For the combustion of $\mathrm{CO}$ and $\mathrm{H}_{2}$, higher reactivity of the manganese minerals compared to ilmenite was found. Among the manganese minerals, the reactivity with $\mathrm{CO}$ and $\mathrm{H}_{2}$ of MnSA, MnGBHNE and MnGBMPB was higher or similar to that of MnBR, which could be taken as reference, as similar samples to this used here have been tested before for CLC applications ${ }^{15}$, including continuous tests in a CLC unit with coal ${ }^{20}$. These facts seem to indicate that the manganese minerals in this work possess enough reactivity to be used in CLC. The high reactivity observed for MnSA during CO combustion is especially interesting, which can be considered as an advantage for further tests of this material in continuous CLC units.

\subsubsection{Evolution of (rate index) $F B$ with the extent of reduction}

Figure 5 shows the (rate index $)_{\mathrm{FB}}$ versus the solid conversion for all the manganese minerals during the cycles where reactivity remained stable. Here the evolution of the reactivity at different extents of reduction can be observed. The (rate index $)_{\mathrm{FB}}$ decreased slightly at high degrees of reduction in the combustion of $\mathrm{CH}_{4}$ and $\mathrm{CO}$. 
This suggested the decrease of reactivity during reduction in the fluidized-bed reactor. Nevertheless, the decrease of reactivity was not relevant for the combustion of $\mathrm{H}_{2}$, since the rate index did not change with the value of solid conversion in Figure 5. The stable rate index during $\mathrm{H}_{2}$ combustion could be attributable to the stable and high reactivity of the manganese minerals with $\mathrm{H}_{2}$. The decrease of reactivity can also be illustrated by the TGA results shown in Figure 2 where the materials used in the fluidized-bed exhibited a decreasing slope of the $X_{\mathrm{r}}$-t curve at high extent of reduction. However, in a practical system high circulation rate of oxygen carrier is required to transfer heat between air and fuel reactors, which means short residence time of oxygen carrier in fuel reactor. In this condition, low extent of reduction of the oxygen carrier always encounter, thus the decrease of reactivity of these manganese minerals would not be of relevance.

\subsection{Reactivity of the used materials in TGA}

The used materials from the fluidized-bed reactor were tested with $\mathrm{CH}_{4}, \mathrm{CO}$ and $\mathrm{H}_{2}$ in TGA at $950^{\circ} \mathrm{C}$ to see the possible changes in reactivity. Figure 2 and Table 3 gathered

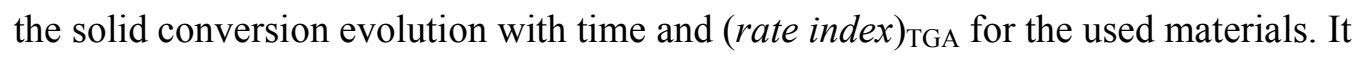
was remarkable that in Figure 2 slower conversion of all the manganese materials in the reaction with $\mathrm{CO}, \mathrm{H}_{2}$ and $\mathrm{CH}_{4}$ was obtained after being used in the fluidized-bed reactor. This led to lower (rate index $)_{\mathrm{TGA}}$ for the used materials (Table 3) which could be attributable to the decrease in the BET surface areas observed in Table 2. Despite 
this, most of the manganese minerals had higher reactivity than ilmenite in terms of $\mathrm{CO}$ and $\mathrm{H}_{2}$ combustion ${ }^{34}$. The used materials exhibited full solid conversion in any case, which indicated that the oxygen transport capacities remained the same as that of the calcined material. The reactivity data of the used materials also allowed estimating the minimum solids inventory in fuel and air reactors to reach $100 \%$ combustion of $\mathrm{CH}_{4}, \mathrm{CO}$ and $\mathrm{H}_{2}$ in the fuel reactor ${ }^{39,40}$. The solids inventory in the fuel reactor needed for $\mathrm{CH}_{4}$ combustion varied from $222 \mathrm{~kg} / \mathrm{MW}_{\text {th }}$ using MnGBMPB to $629 \mathrm{~kg} / \mathrm{MW}_{\text {th }}$ using MnSA. These values are larger than the value corresponding to ilmenite $\left(167 \mathrm{~kg} / \mathrm{MW}_{\text {th }}\right)$. However, during CO combustion lower solids inventory than for ilmenite was required for the MnSA material $\left(63 \mathrm{~kg} / \mathrm{MW}_{\text {th }}\right)$ due to the high reactivity of MnSA with $\mathrm{CO}$. In the case of $\mathrm{H}_{2}$, similar solids inventory to that corresponding to ilmenite were required for all the materials $\left(27-44 \mathrm{~kg} / \mathrm{MW}_{\text {th }}\right)$. On the other hand, the inventory required for the oxidation process is remarkably lower than that for the reduction step and it is in the range $30-71 \mathrm{~kg} / \mathrm{MW}_{\text {th }}$ depending on the fuel and material used.

The low inventory for $\mathrm{CO}$ and $\mathrm{H}_{2}$ combustion using the MnSA can be accounted as an advantage for the use of this material in $i \mathrm{G}-\mathrm{CLC}$ with coal as $\mathrm{CO}$ and $\mathrm{H}_{2}$ are the main gases from char gasification. Therefore, the MnSA mineral can be considered as a promising oxygen carrier for further testing in $i \mathrm{G}-\mathrm{CLC}$ with coal. 


\section{Physical characterization}

\subsection{Porosity distribution}

The distribution of pores in both calcined and used samples is shown in Figure 6.

Before the tests in the fluidized-bed reactor the pores were composed of macropores

$(d>50 \mathrm{~nm})$ and some mesopores $(2<d<50 \mathrm{~nm})$, except for MnSA which showed only

macropores. After reaction in the fluidized-bed reactor, mesopores were completely

developed to macro pores, resulting in the disappearance of pores smaller than $50 \mathrm{~nm}$.

For calcined and used MnGBHNE, MnGBMPB and MnBR a bimodal distribution

could be observed regarding the macro scale with $d<10000 \mathrm{~nm}$ and $d>10000 \mathrm{~nm}$. A

decrease in porosity of the used MnGBHNE and MnBR was observed at $d<10000 \mathrm{~nm}$

in Figure 6 and the values included in Table 2. Results in Figure 6 can be also linked

to the changes observed by SEM analysis shown in Figure 7. The big holes in Figure

7 are related to the peak at $d>10000 \mathrm{~nm}$ in the used materials and cannot be identified

as porosity. For the MnSA mineral, bimodal distribution of pore size and holes inside

particle were not observed both for calcined and used samples. Nevertheless, the

amount of pores smaller than $10000 \mathrm{~nm}$ was raised in the used MnSA, which led to

the increase of porosity in Table 2. Combining the shifts of pores from meso to macro and the holes appeared in Figure 7, the decrease of bulk density of the used particles

in Table 2 was reasonable. 
It was noticed that in Figures 6 and 7 pores inside the particle were developed after the use in fluidized-bed reactor. Therefore, Figure 8 compared the particle size distributions of the calcined and the used manganese minerals. In accordance with the findings in a previous work ${ }^{15}$, significant expansion of particles was observed for the used materials, except for the MnGBHNE. The change in the particle size distribution found for MnSA might be caused by the increase in porosity of this material, see Table 2. In the cases of MnGBMPB and MnBR, the big holes appeared in the used particles in Figure 7 might be a reason for the increase of particle size. However, for MnGBHNE smaller holes were found in the used particles, which resulted in less expansion.

\subsection{Fluidization behavior: agglomeration and attrition rate}

For all the manganese minerals, neither de-fluidization nor agglomeration of particles was observed during the tests in the fluidized-bed reactor, even when particles were highly reduced. This fact was confirmed by SEM analysis of the used particles in Figure 7 where agglomeration was not observed. Attrition generated by collision and abrasiveness produced fine particles. In this work, the attrition rate was calculated considering the elutriated particles smaller than $40 \mu \mathrm{m}$ as unrecoverable fines. Figure 9 (a) plotted the attrition rates for the manganese minerals as a function of cycles. It was observed that the MnSA maintained low attrition rate for all the cycles. In contrast, the attrition rate of MnBR notably increased with the number of cycles up to 
$0.73 \% / \mathrm{h}$ in the end of tests. For MnGBHNE and MnGBMPB the attrition rates were lower than for MnBR after 40 cycles, although slightly higher than that found for MnSA. Notably, the MnSA and MnGBHNE minerals possessed similar attrition rates to ilmenite ${ }^{29}$ which was considered for scale-up to $50 \mathrm{~kW}-1 \mathrm{MW}$ continuous CLC units $^{8,11,12}$. The attrition rate can be related to the crushing strength of the particles. Samples were extracted at different operation cycles and subjected to determine the crushing strength. Figure 9 (b) plotted the crushing strength of the four the manganese minerals as a function of the number of cycles. Generally, the crushing strength of each mineral decreased with cycles, attributable to the development of pores and the appearance of holes in the particles, as shown in Figures 6 and 7. More in detail, the MnSA initially possessed a high crushing strength of $4.6 \mathrm{~N}$ that was decreased to 2.0 $\mathrm{N}$ after 40 cycles (Table 2). In the case of MnGBHNE, the crushing strength was reduced slowly during operation from 1.8 to $1.4 \mathrm{~N}$ after 58 cycles. In both cases, the crushing strength is similar to that for activated ilmenite after similar numbers of cycles $^{29}$, which was higher than the minimum value to allow operation in a CLC system, $1 \mathrm{~N}$. Thus low attrition rates for MnSA and MnGBHNE were observed in Figure 9 (a). On the contrary, the crushing strength of MnGBMPB and MnBR was lower than $1 \mathrm{~N}$ after 40 cycles, which may cause the increase in the attrition rate observed both for MnGBMPB and MnBR in Figure 9 (a).

Normally, attrition can affect the lifetime of the materials used for CLC. High attrition rate can increase the amount of fine particles produced, thus decrease the lifetime. 
The attrition rate of MnSA and MnGBHNE was moderate, which corresponded to an average lifetime of 1600 and $1000 \mathrm{~h}$, respectively. For MnGBMPB and MnBR the corresponding lifetime would be 360 and $150 \mathrm{~h}$, respectively, making them less attractive for long-term use. In the case of MnGBMPB, this is in accordance with the value of AJI calculated for the used sample. Following the results from Gayán et al. ${ }^{23}$, the oxygen carriers with AJI values higher than $15-20 \%$ after their use in a CLC unit should improve their attrition performance before being selected for scale-up.

However, despite the high attrition rate observed and the low crushing strength after use in the fluidized-bed reactor, the MnBR sample presented a value for AJI lower than $15 \%$. According to the particle size distributions shown in Figure 10, this can be due to the breaking behavior of MnBR particles under the conditions used in the attrition tester. Figure 10 compared the distribution corresponding to the MnBR sample after use in the fluidized-bed reactor and that corresponding to the used particles after testing following the ASTM D5757-00 standard ${ }^{24}$. As it is observed, the original distribution turns into a bimodal distribution, which supports the idea of breakage of the particles during the tests. The average size of the smallest fraction of those broken particles is around $40 \mu \mathrm{m}$. However, these particles remained in the bed after the tests in attrition tester. The particles considered to calculate the AJI value are only those recovered in the filter at the outlet of the system for the AJI determination and they are less than $20 \mu \mathrm{m}$ in size. However, these broken particles do escape from the fluidized-bed batch reactor during the experiments with gaseous fuels, and were retained in the filters at the outlet of fluidized-bed reactor and therefore considered in 
the calculation of the attrition rate. This would explain the apparent discrepancy between attrition rate and AJI value.

\section{Conclusion}

Four manganese minerals, i.e. MnSA, MnGBHNE, MnGBMPB and MnBR, were studied in a TGA apparatus and a fluidized-bed batch reactor with gaseous fuels, $\mathrm{CH}_{4}$, $\mathrm{CO}$ and $\mathrm{H}_{2}$. The performance of these materials in chemical looping combustion (CLC) and chemical looping with oxygen uncoupling (CLOU) was evaluated. The four studied minerals exhibited no cyclic release and uptake of gaseous oxygen due to the unfeasibility of the regeneration of $\mathrm{Mn}_{2} \mathrm{O}_{3}$ from $\mathrm{Mn}_{3} \mathrm{O}_{4}$, so these materials were not suitable for CLOU. During the redox cycles with gaseous fuels in a fluidized-bed reactor, absence of agglomeration was found, even at high degrees of solids conversion.

Decreases of reactivity were seen for all the manganese minerals for the first 10 cycles in the fluidized-bed reactor. Stable reactivity of the materials was achieved after 10 cycles with $\mathrm{CH}_{4}$, which was maintained to the end of the tests involved in this work. The reactivity with $\mathrm{CH}_{4}$ of these manganese minerals is lower than previously tested Fe-based materials. However, high reactivity and low solids inventory were found during the combustion of $\mathrm{CO}$ and $\mathrm{H}_{2}$ with these manganese minerals. 
Remarkably, extremely low solids inventory was required for the use of MnSA during the combustion of $\mathrm{CO}$ and $\mathrm{H}_{2}$.

After the tests with the gaseous fuels, some changes were found in the materials. Pores distributed inside the particles were developed, which resulted in the transition of meso pores to the macro pores in the after-used particles. Therefore, expansion of particles and decrease of crushing strength were observed for the manganese materials during the tests. The MnBR sample showed a sharp decrease of crushing strength and produced high amount of fines, which makes this material unsuitable after 40 cycles of operation. This trend, but a lower degree, was observed for MnGBMPB. Low attrition rates of particles and adequate crushing strength were found for the MnSA and MnGBHNE manganese minerals during the operation period. When both reactivity and attrition rate were evaluated, MnSA and MnGBHNE are more suggestible for further tests in CLC.

\section{ASSOCIATED CONTENT}

Supporting Information Available. Determination of the active composition and the oxygen transport capacity of manganese minerals from TGA experiments.

This material is available free of charge via the Internet at http://pubs.acs.org 


\section{Nomenclature}

d pore size of solid particles, $\mathrm{nm}$

$\left(d X_{i} / d t\right)_{\exp } \quad$ reaction rate of solids calculated from experimental data for reduction $(i=\mathrm{r})$ or oxidization $(i=\mathrm{o}), \mathrm{s}^{-1}$

$\left(d X_{i} / d t\right)_{\text {norm }}$ normalized reactivity of solids for reduction $(i=\mathrm{r})$ or oxidization $(i=\mathrm{o}), \mathrm{s}^{-1}$

$F_{\mathrm{i}}$ molar flow rate of stream at inlet $(i=\mathrm{in})$ or outlet $(i=\mathrm{out}), \mathrm{mol} \cdot \mathrm{s}^{-1}$

$m$ instantaneous mass of the manganese mineral material, $\mathrm{kg}$

$M_{\mathrm{O}}$ molecular weight of oxygen, $16 \cdot 10^{-3} \mathrm{~kg} / \mathrm{mol}$

$m_{i} \quad$ mass of fully oxidized $(i=\mathrm{o})$ or reduced $(i=\mathrm{r})$ manganese minerals, $\mathrm{kg}$

$p_{i} \quad$ partial pressure of gaseous fuels inlet $(i=\mathrm{in})$ or outlet $(i=$ out $)$ the fluidized-bed

reactor, atm

$p_{\mathrm{m}}$ average pressure of gaseous fuels in the fluidized-bed reactor, atm

$p_{\text {ref }}$ a reference partial pressure, atm

$p_{\mathrm{TGA}} \quad$ partial pressure of gas used in TGA, atm

$(\text { rate index })_{\mathrm{FB}} \quad$ rate index determined in fluidized-bed tests, $\% / \mathrm{min}$

$(\text { rate index })_{\mathrm{TGA}}$ rate index determined in TGA tests, $\% / \mathrm{min}$

$R_{\mathrm{OC}}$ oxygen transport capacity for the manganese mineral

$r_{\mathrm{O}}(t)$ molar rate of atomic oxygen transference from the manganese minerals to the

fuels, $\mathrm{molO} \cdot \mathrm{s}^{-1}$

$t \quad$ reaction time, $\mathrm{s}$

$t_{0, i}$ time at the beginning of oxidation $(i=\mathrm{o})$ or reduction $(i=\mathrm{r})$ process, $\mathrm{s}$

$V$ volume of pores in the manganese mineral particles, $\mathrm{cm}^{3} / \mathrm{g}$ 
$X_{i}$ solids conversion referred to the reduction $(i=\mathrm{r})$ or oxidization $(i=\mathrm{o})$ process

$X_{\mathrm{o}, \text { redf }}$ solids conversion at the end of reduction step

Greek symbols

$\varepsilon_{\mathrm{g}} \quad$ expansion factor of gas mixture

$\left(\chi_{i}\right)_{\text {in }} \quad$ molar fraction of the gas $i\left(i=\mathrm{CO}, \mathrm{CO}_{2}, \mathrm{H}_{2} \mathrm{O}\right.$ or $\left.\mathrm{O}_{2}\right)$ inlet the reactor

$\left(\chi_{i}\right)_{\text {out }} \quad$ molar fraction of the gas $i\left(i=\mathrm{CO}, \mathrm{CO}_{2}, \mathrm{H}_{2} \mathrm{O}\right.$ or $\left.\mathrm{O}_{2}\right)$ outlet the reactor

Acronyms

AJI Air Jet Attrition Index

BET Brunauer-Emmett-Teller

CLC chemical looping combustion

CLOU chemical looping with oxygen uncoupling

ICP-AES inductively coupled plasma atomic emission spectroscopy

$i$ G-CLC in situ gasification chemical looping combustion

NDIR non-dispersive infrared analyzer

OC oxygen carrier

PSD particle size distribution

SEM scanning electron microscope

TCD thermal conductivity detector

TGA thermogravimetric analyzer

TPD temperature programmed decomposition

TPO temperature programmed oxidation

XRD X-ray diffraction 


\section{Acknowledgments}

This work was supported by the Spanish Ministry of Economy and Competitiveness (project ENE 2013-45454-R), by the European Regional Development Fund (ERDF), by the CSIC (project 2014-80E101) and by the Government of Aragón (Spain, Ref. T06). T. Mendiara thanks for the "Ramón y Cajal" post-doctoral contract awarded by the Spanish Ministry of Economy and Competitiveness. D. Mei is grateful for the support provided by the China Scholarship Council (CSC201306160054). The authors also thank Hidro Nitro Española S.A. for providing MnSA and MnGBHNE materials and Leopoldo Alcázar (CT-GAS) for providing the MnBR material. 


\section{References}

(1) IEA. World Energy Outlook 2013; OECD/IEA: Paris, France, 2013.

(2) Kerr, H. R. Capture and Separation Technology Gaps and Priority Research

Needs. In Carbon Dioxide Capture for Storage in Deep Geologic Formations;

Elsevier Science: Amsterdam, 2005.

(3) Mendiara, T.; García-Labiano, F.; Gayán, P.; Abad, A.; de Diego, L. F.; Adánez, J. Fuel 2013, 106, 814-826.

(4) Dennis, J. S.; Scott, S. A.; Hayhurst, A. N. J. Energy Inst. 2006, 79, 187-190.

(5) Mattisson, T.; Lyngfelt, A.; Leion, H. Int. J. Greenhouse Gas Control 2009, 3, 11-19.

(6) Adánez, J.; Abad, A.; García-Labiano, F.; Gayán, P.; de Diego, L. F. Prog. Energy Combust. Sci. 2012, 38, 215-282.

(7) Cuadrat, A.; Abad, A.; García-Labiano, F.; Gayán, P.; de Diego, L. F.; Adánez, J. Int. J. Greenhouse Gas Control 2011, 5, 1630-1642.

(8) Markström, P.; Linderholm, C.; Lyngfelt, A. Int. J. Greenhouse Gas Control 2013, $15,150-162$.

(9) Mendiara, T.; de Diego, L. F.; García-Labiano, F.; Gayán, P.; Abad, A.; Adánez, J. Int. J. Greenhouse Gas Control 2013, 17, 170-182.

(10)Mendiara, T.; de Diego, L. F.; García-Labiano, F.; Gayán, P.; Abad, A.; Adánez, J. Fuel 2014, 126, 239-249.

(11) Ströhle, J.; Orth, M.; Epple, B. Appl. Energy 2014, 113, 1490-1495. 
(12)Abad, A.; Pérez-Vega, R.; de Diego, L. F.; García-Labiano, F.; Gayán, P.;

Adánez, J. Appl. Energy 2015, DOI: 10.1016/j.apenergy.2015.03.094.

(13)Larring, Y.; Braley, C.; Pishahang, M.; Andreassen, K. A.; Bredesen, R. Energy

Fuels 2015, 29, 3438-3445.

(14)Frohn, P.; Arjmand, M.; Azimi, G.; Leion, H.; Mattisson, T.; Lyngfelt, A. AIChE

J. 2013, 59, 4346-4354.

(15) Arjmand, M.; Leion, H.; Mattisson, T.; Lyngfelt, A. Appl. Energy 2014, 113, 1883-1894.

(16) Sundqvist, S.; Arjmand, M.; Mattisson, T.; Leion, H.; Rydén, M.; Lyngfelt, A. In Proceedings of the 11th International Conference on Fluidized Bed technology, Beijing, 2014.

(17)Fossdal, A.; Bakken, E.; Øye, B. A.; Schøning, C.; Kaus, I.; Mokkelbost, T.; Larring, Y. Int. J. Greenhouse Gas Control 2011, 5, 483-488.

(18)Leion, H.; Mattisson, T.; Lyngfelt, A. Energy Fuels 2009, 23, 2307-2315.

(19)Larring, Y.; Pishahang, M.; Sunding, M.F.; Tsakalakis, K. Fuel 2015, 159, 169-178.

(20)Linderholm, C.; Lyngfelt, A.; Cuadrat, A.; Jerndal, E. Fuel 2012, 102, 808-822.

(21) Arjmand, M.; Leion, H.; Lyngfelt, A.; Mattisson, T. Int. J. Greenhouse Gas

Control 2012, 8, 56-60.

(22) Yazdanpanah, M.; Forret, A.; Gauthier, T. Appl. Energy 2015, DOI:10.1016/j.apenergy.2015.07.015 
(23) Gayán, P.; García-Labiano, F.; Cabello, A.; de Diego, L.F.; Abad, A.; Adánez, J. $22^{\text {nd }}$ Fluidized Bed Conversion Conference. 2015 (Turku) Finland.

(24)ASTM D5757-00: Standard Test Method for Determination of Attrition and Abrasion of Powdered Catalysts by Air Jets, ASTM, Philadelphia, United States, 2000.

(25) Johansson, M.; Mattisson, T.; Lyngfelt, A. Ind. Eng. Chem. Res. 2004, 43, 6978-6987.

(26) Adánez, J.; de Diego, L. F.; García-Labiano, F.; Gayán, P.; Abad, A.; Palacios, J. M. Energy Fuels 2004, 18, 371-377.

(27) Abad, A.; García-Labiano, F.; de Diego, L. F.; Gayán, P.; Adánez, J. Energy Fuels 2007, 21, 1843-1853.

(28) Abad, A.; Adánez, J.; García-Labiano, F.; de Diego, L. F.; Gayán, P.; Celaya, J. Chem. Eng. Sci. 2007, 62, 533-549.

(29)Cuadrat, A.; Abad, A.; Adánez, J.; de Diego, L. F.; García-Labiano, F.; Gayán, P. Fuel Process. Technol. 2012, 94, 101-112.

(30)Mendiara, T.; Abad, A.; de Diego, L. F.; García-Labiano, F.; Gayán, P.; Adánez, J. Energy Fuels 2012, 26, 1420-1431.

(31)Adánez-Rubio, I.; Gayán, P.; Abad, A.; de Diego, L. F.; García-Labiano, F.; Adánez, J. Energy Fuels 2012, 26, 3069-3081.

(32)Mei, D.; Abad, A.; Zhao, H.; Adánez, J. Fuel Process. Technol. 2015, 133, 210-219. 
(33) Adánez-Rubio, I.; Gayán, P.; Abad, A.; García-Labiano, F.; de Diego, L. F.;

Adánez, J. Chem. Eng. J. 2014, 256, 69-84.

(34)Mendiara, T.; Pérez, R.; Abad, A.; de Diego, L. F.; García-Labiano, F.; Gayán, P.; Adánez, J. Ind. Eng. Chem. Res. 2012, 51, 16216-16229.

(35)Ortiz, M.; Gayán, P.; de Diego, L. F.; García-Labiano, F.; Abad, A.; Pans, M. A.; Adánez, J. J. Power Sources 2011, 196, 4370-4381.

(36) Abad, A.; Mattisson, T.; Lyngfelt, A.; Johansson, M. Fuel 2007, 86, 1021-1035.

(37)Levenspiel, O. Chemical reaction engineering, 2nd ed.; Wiley: New York, 1972.

(38)Abad, A.; Adánez, J.; García-Labiano, F.; de Diego, L.F.; Gayán, P. Combust.

Flame 2010, 157, 602-615.

(39) Abad, A.; Adánez, J.; Cuadrat, A.; García-Labiano, F.; Gayán, P.; de Diego, L. F. Chem. Eng. Sci. 2011, 66, 689-702.

(40)Adánez, J.; Cuadrat, A.; Abad, A.; Gayán, P.; de Diego, L. F.; García-Labiano, F. Energy Fuels 2010, 24, 1402-1413. 


\section{Figure Captions}

Figure 1 Setup of the batch fluidized-bed reactor

Figure 2 Solid conversion as a function of time at $950^{\circ} \mathrm{C}$ for the calcined manganese minerals during the reactions with $\mathrm{CH}_{4}(-), \mathrm{CO}(-), \mathrm{H}_{2}(-)$; and for the used materials with $\mathrm{CH}_{4}(--), \mathrm{CO}(-\bullet-), \mathrm{H}_{2}(\bullet \bullet \bullet \bullet)$

Figure 3 Wet-basis gas concentration and solid conversion in the combustion of $25 \%$

$\mathrm{CH}_{4}, 50 \% \mathrm{CO}$ and $50 \% \mathrm{H}_{2}$ using the MnSA manganese mineral at $950^{\circ} \mathrm{C}$;

red $=$ reduction, oxi $=$ oxidation

Figure 4 Rate index, $(\text { rate index })_{\mathrm{FB}}$, for $\operatorname{MnSA}(\boldsymbol{\square}), \operatorname{MnGBHNE}(\boldsymbol{\nabla}), \operatorname{MnGBMPB}(\triangle)$ and $\mathrm{MnBR}(\mathrm{O})$, as a function of cycles during the combustion of $\mathrm{CH}_{4}, \mathrm{CO}$ and $\mathrm{H}_{2}$ in the fluidized-bed reactor; rate index at $950^{\circ} \mathrm{C}$ of activated ilmenite (-..-) estimated from Cuadrat et al. ${ }^{29}$ and for bauxite waste (-) from Mendiara et al. ${ }^{30}$

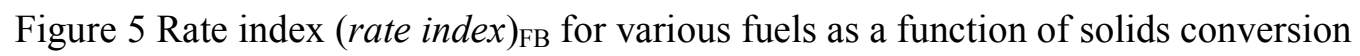
using $\operatorname{MnSA}(-), \operatorname{MnGBHNE}(-), \operatorname{MnGBMPB}(-)$ and $\operatorname{MnBR}(-)$ as bed materials in the fluidized-bed reactor.

Figure 6 Pore size distributions of calcined (continuous lines) and the used (dash-dot lines) manganese minerals

Figure 7 Morphology analyses of the calcined (a-d) and used materials (e-1) in terms of the cross sections, for the manganese minerals: MnSA (a, e, i), MnGBHNE (b, f, j), $\operatorname{MnGBMPB}(\mathrm{c}, \mathrm{g}, \mathrm{k})$ and $\operatorname{MnBR}(\mathrm{d}, \mathrm{h}, \mathrm{l})$

Figure 8 Particle size distributions of the calcined (continuous lines) and the used (dash-dot lines) manganese minerals 
Figure 9 Attrition rates (a) and crushing strength (b) with cycles for the manganese

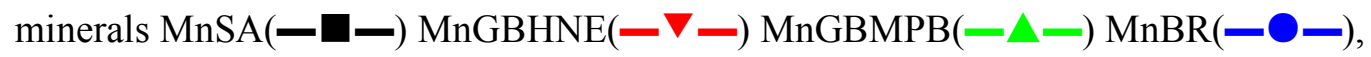
the horizontal dash line with the value $1 \mathrm{~N}$ represents the minimum desirable crushing strength of particles

Figure 10 Particle size distribution of the MnBR sample after use in the fluidized-bed batch reactor (dash-dot line) and after the AJI test (dash lines) 
Figure 1 Setup of the batch fluidized-bed reactor

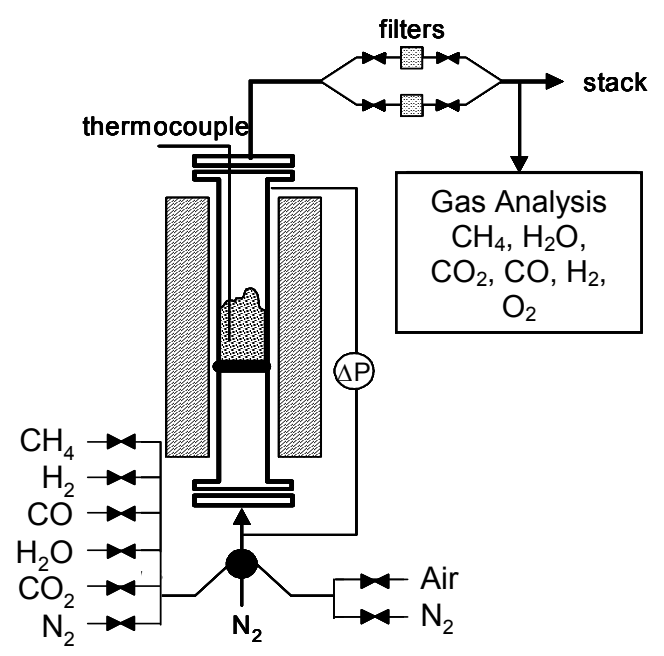


1

2

3

4

5

6

7

8

9

10

11

12

13

14

15

16

17

18

19

20

21

22

23

24

25

26

27

28

29

30

31

32

33

34

35

36

37

38

39

40

41

42

43

44

45

46

47

48

49

50

51

52

53

54

55

56

57

58

59

60

Figure 2 Solid conversion as a function of time at $950^{\circ} \mathrm{C}$ for the calcined manganese minerals during the reactions with $\mathrm{CH}_{4}(-), \mathrm{CO}(-), \mathrm{H}_{2}(-)$; and for the used materials with $\mathrm{CH}_{4}(-\boldsymbol{-}), \mathrm{CO}(-\bullet-), \mathrm{H}_{2}(\bullet \bullet \bullet \bullet)$

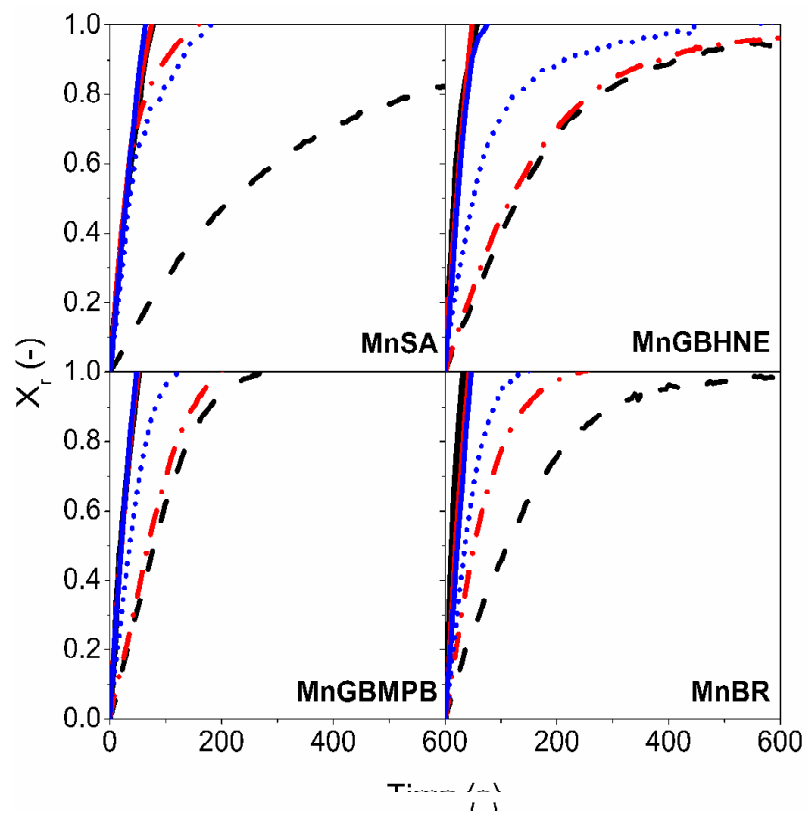


Figure 3 Wet-basis gas concentration and solid conversion in the combustion of $25 \%$ $\mathrm{CH}_{4}, 50 \% \mathrm{CO}$ and $50 \% \mathrm{H}_{2}$ using the MnSA manganese mineral at $950^{\circ} \mathrm{C}$; red=reduction, oxi $=$ oxidation

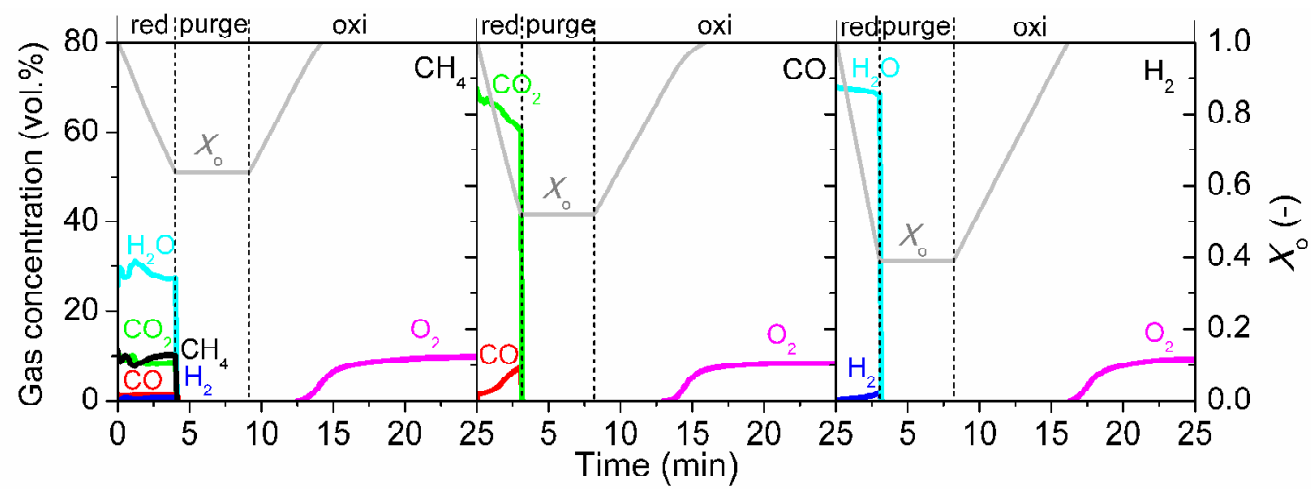

22

23

24

25

26

27

28

29

30

31

32

33

34

35

36

37

38

39

40

41

42

43

44

45

46

47

48

49

50

51

52

53

54

55

56

57

58

59

60 
Figure 4 Rate index, $(\text { rate index })_{\mathrm{FB}}$, for $\operatorname{MnSA}(\boldsymbol{\square}), \operatorname{MnGBHNE}(\boldsymbol{\nabla}), \operatorname{MnGBMPB}(\triangle)$ and $\mathrm{MnBR}(\mathrm{O})$, as a function of cycles during the combustion of $\mathrm{CH}_{4}, \mathrm{CO}$ and $\mathrm{H}_{2}$ in the fluidized-bed reactor; rate index at $950^{\circ} \mathrm{C}$ of activated ilmenite (-..-) estimated from Cuadrat et al. ${ }^{29}$ and for bauxite waste (-) from Mendiara et al. ${ }^{30}$

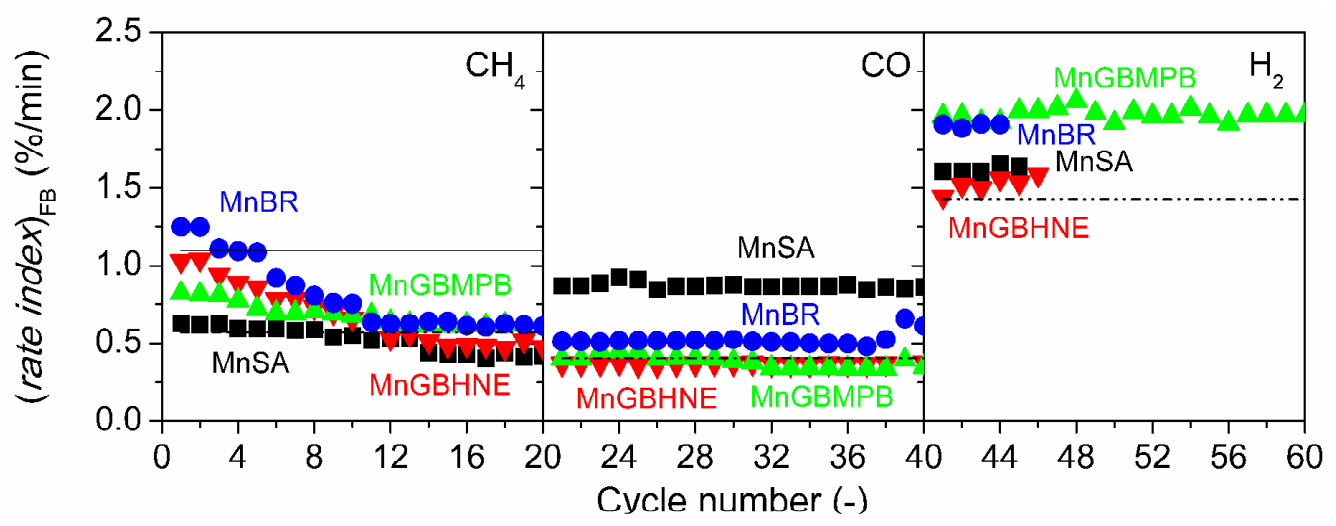

25

26 
Figure 5 Rate index (rate index $)_{\mathrm{FB}}$ for various fuels as a function of solids conversion using $\operatorname{MnSA}(-), \operatorname{MnGBHNE}(-), \operatorname{MnGBMPB}(-)$ and $\operatorname{MnBR}(-)$ as bed materials in the fluidized-bed reactor.

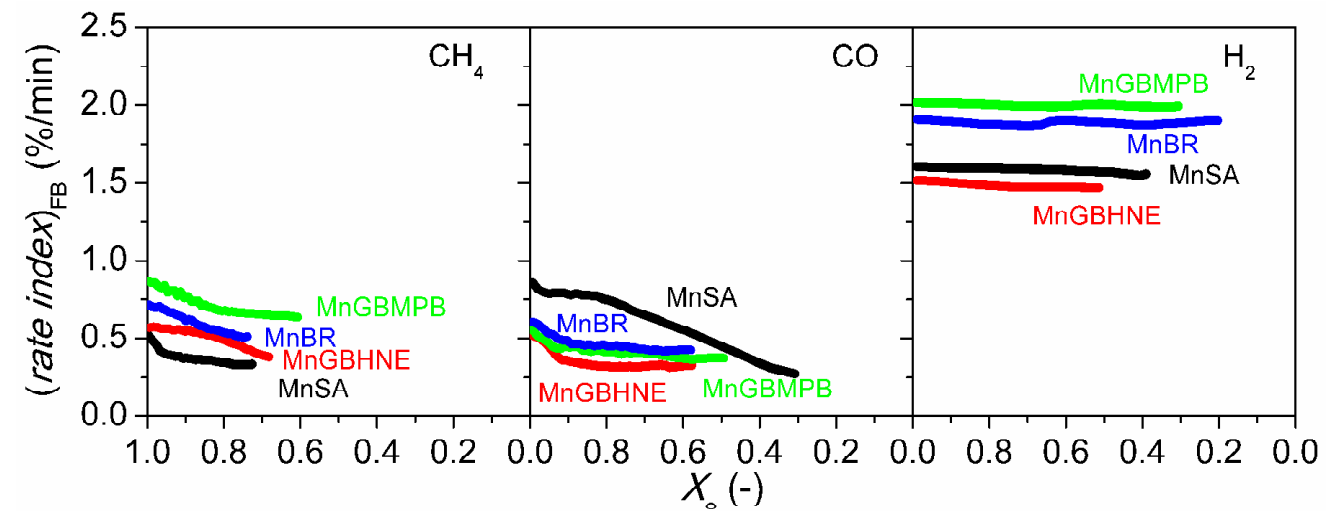


Figure 6 Pore size distributions of calcined (continuous lines) and the used (dash-dot lines) manganese minerals

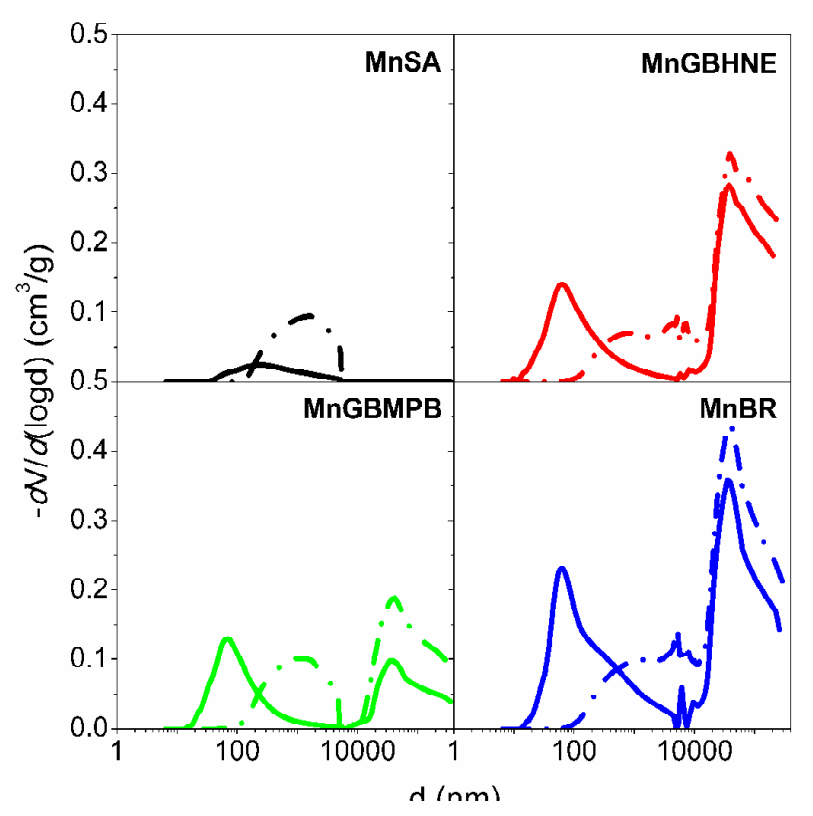

1

2

5

6

7

8

10

11

12

13

14

15

16

17

18

19

20

21

22

23

24

25

26

27

28

29

30

31

32

33

34

35

36

37

38

39

40

41

42

43

44

45

46

47

48

49

50

51

52

53

54

55

56

57

58

59

60 
Figure 7 Morphology analyses of the calcined (a-d) and used materials (e-l) in terms of the cross sections, for the manganese minerals: MnSA (a, e, i), MnGBHNE (b, f, j), $\operatorname{MnGBMPB}(\mathrm{c}, \mathrm{g}, \mathrm{k})$ and $\operatorname{MnBR}(\mathrm{d}, \mathrm{h}, \mathrm{l})$

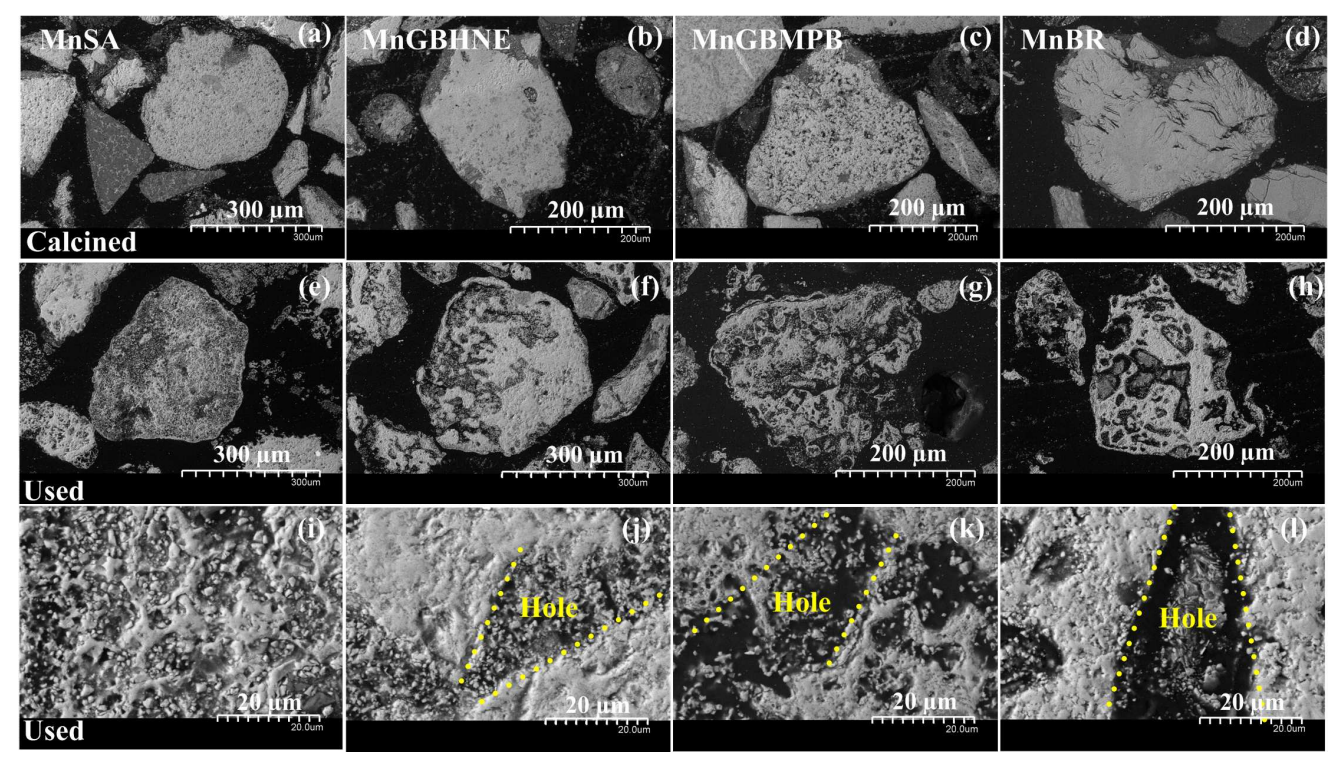


Figure 8 Particle size distributions of the calcined (continuous lines) and the used (dash-dot lines) manganese minerals

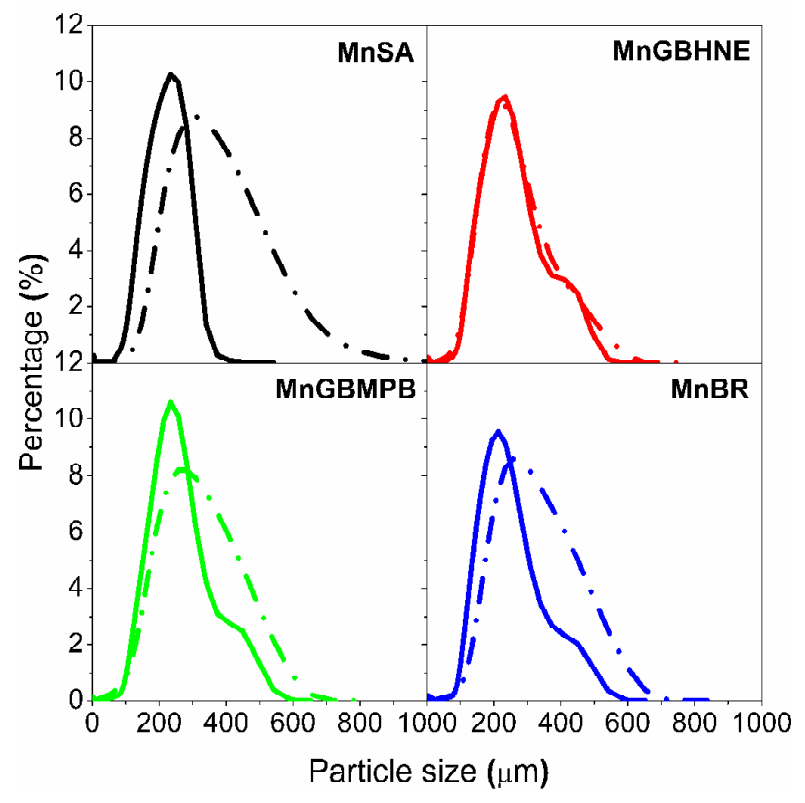

29

30

31

32

33

34

35

36

37

38

39

40

41

42

43

44

45

46

47

48

49

50

51

52

53

54

55

56

57

58

59

60 
Figure 9 Attrition rates (a) and crushing strength (b) with cycles for the manganese

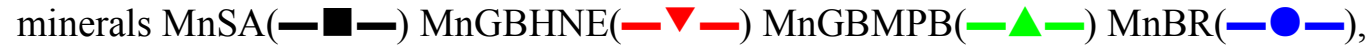
the horizontal dash line with the value $1 \mathrm{~N}$ represents the minimum desirable crushing strength of particles
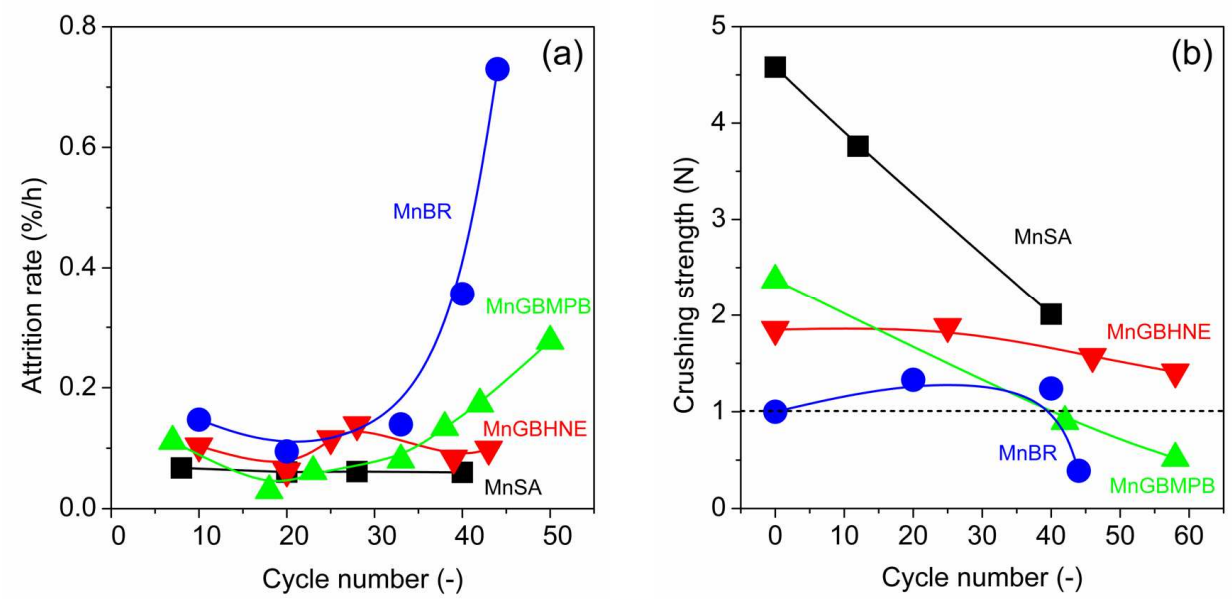

29

30

31

32

33

34

35

36

37

38

39

40

41

42

43

44

45

46

47

48

49

50

51

52

53

54

55

56

57

58

59

60 
Figure 10 Particle size distribution of the MnBR sample after use in the fluidized-bed batch reactor (dash-dot line) and after the AJI test (dash lines)

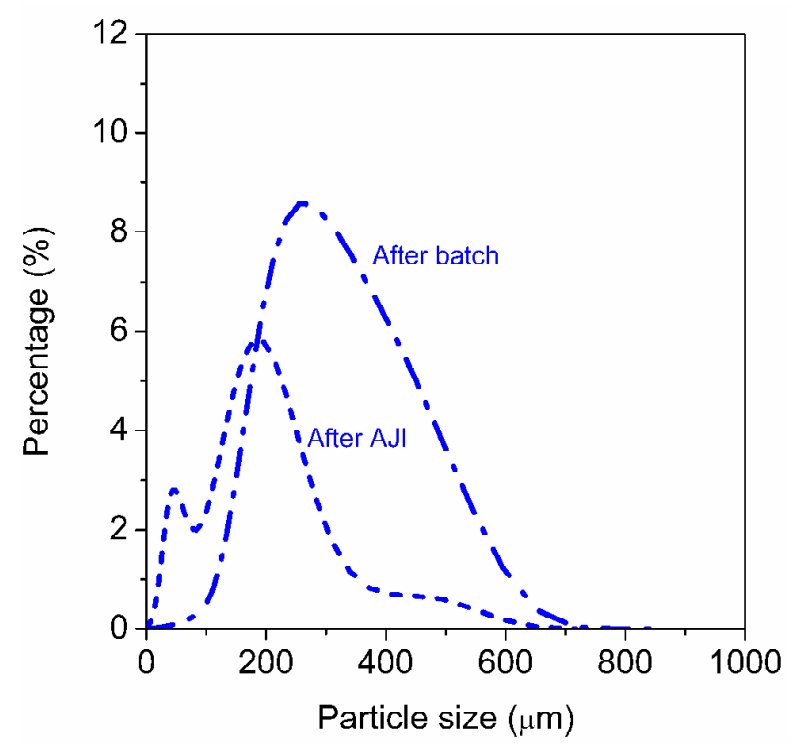

27

28

29

30

31

32

33

34

35

36

37

38

39

40

41

42

43

44

45

46

47

48

49

50

51

52

53

54

55

56

57

58

59

60 


\section{Table Captions}

Table 1 Composition of the four manganese minerals calcined at $800^{\circ} \mathrm{C}$ for $2 \mathrm{~h}$

Table 2 Active component composition and properties of calcined and used

manganese minerals

Table 3 Rate index $(\% / \mathrm{min})$ from TGA tests at $950^{\circ} \mathrm{C}$, for the calcined and used

manganese minerals, a Mn ore, two Fe-Mn based materials and some Fe-based

materials.

Table 4 Minimum solids inventory ( $\mathrm{kg}$ solids per $\mathrm{MW}_{\text {th }}$ of fuel) required in fuel and air reactors to reach $100 \%$ combustion efficiency of $\mathrm{CH}_{4}, \mathrm{CO}, \mathrm{H}_{2}$ at $950^{\circ} \mathrm{C}$. 
Table 1 Composition of the four manganese minerals calcined at $800^{\circ} \mathrm{C}$ for $2 \mathrm{~h}$

\begin{tabular}{|c|c|c|c|c|}
\hline & MnSA & MnGBHNE & MnGBMPB & MnBR \\
\hline \multicolumn{5}{|c|}{ XRD main phases } \\
\hline & $\mathrm{Mn}_{2} \mathrm{O}_{3}, \mathrm{Mn}_{3} \mathrm{O}_{4}$ & $\mathrm{Mn}_{2} \mathrm{O}_{3}$ & $\mathrm{Mn}_{2} \mathrm{O}_{3}$ & $\mathrm{Mn}_{2} \mathrm{O}_{3}, \mathrm{Mn}_{3} \mathrm{O}_{4}$ \\
\hline & \multirow[t]{2}{*}{$\mathrm{Fe}_{2} \mathrm{O}_{3}$} & $\mathrm{Fe}_{2} \mathrm{O}_{3}$ & $\mathrm{Fe}_{2} \mathrm{O}_{3}$ & $\mathrm{Fe}_{2} \mathrm{O}_{3}$ \\
\hline & & $\mathrm{SiO}_{2}$ & $\mathrm{SiO}_{2}$ & $\mathrm{SiO}_{2}$ \\
\hline \multicolumn{5}{|c|}{ Element distribution (wt.\%) } \\
\hline $\mathrm{Mn}$ & $39.8(39.9)$ & $46.6(47.1)$ & $53.0(56.0)$ & $44.6(50.3)$ \\
\hline $\mathrm{Fe}$ & $14.6(13.9)$ & $5.1(5.7)$ & $3.6(3.5)$ & $5.2(4.0)$ \\
\hline $\mathrm{Si}$ & 3.3 & 4.2 & 1.6 & 4.1 \\
\hline $\mathrm{Al}$ & 0.2 & 3.8 & 2.8 & 4.1 \\
\hline $\mathrm{O}$ & 36.2 & 38.4 & 37.5 & 38.9 \\
\hline
\end{tabular}

Composition was determined by ICP-AES, excepting numbers in brackets, which were determined by TGA, described in Supporting Information. Minor amount of $\mathrm{Mg}$, $\mathrm{Ti}, \mathrm{Ca}, \mathrm{Na}$ and $\mathrm{K}$ were also detected. Oxygen was determined by difference 
Table 2 Active component composition and properties of calcined and used manganese minerals

\begin{tabular}{|c|c|c|c|c|}
\hline \multirow{3}{*}{ Redox composition (wt.\%) } & MnSA & MnGBHNE & MnGBMPB & MnBR \\
\hline & $65.6 \mathrm{Mn}_{3} \mathrm{O}_{4}$ & $67.5 \mathrm{Mn}_{3} \mathrm{O}_{4}$ & $80.7 \mathrm{Mn}_{3} \mathrm{O}_{4}$ & $71.8 \mathrm{Mn}_{3} \mathrm{O}_{4}$ \\
\hline & $18.6 \mathrm{Fe}_{2} \mathrm{O}_{3}$ & $8.4 \mathrm{Fe}_{2} \mathrm{O}_{3}$ & $5.2 \mathrm{Fe}_{2} \mathrm{O}_{3}$ & $6.0 \mathrm{Fe}_{2} \mathrm{O}_{3}$ \\
\hline Bulk density (kg/m³) & $3510(1860)^{\mathrm{b}}$ & $2570(2290)$ & $2900(1690)$ & $2230(1800)$ \\
\hline BET surface area $\left(\mathrm{m}^{2} / \mathrm{g}\right)$ & $0.6(0.3)$ & $10.1(0.5)$ & $7.4(0.5)$ & $12.2(0.5)$ \\
\hline Porosity (vol.\%) & $12.3(28.2)$ & $35.7(25.4)$ & $30.2(32.9)$ & $47.3(31.7)$ \\
\hline Crushing strength $(\mathrm{N})$ & $4.6(2.0)$ & $1.8(1.4)$ & $2.4(0.5)$ & $1.0(0.4)$ \\
\hline AJI (\%) & $5.5(14.4)$ & $16.8(14.6)$ & $16.6(22.1)$ & $26.6(11.8)$ \\
\hline Oxygen transport capacity & 4.7 & 5.0 & 5.8 & 5.2 \\
\hline (wt.\%) & & & & \\
\hline
\end{tabular}

${ }^{\mathrm{a}}$ determined by TGA, see Supporting Information; ()$^{\mathrm{b}}$ for the used materials 
Table 3 Rate index $(\% / \mathrm{min})$ from TGA tests at $950^{\circ} \mathrm{C}$, for the calcined and used manganese minerals, a Mn ore, two Fe-Mn based materials and some Fe-based materials.

\begin{tabular}{lllll}
\hline & \multicolumn{1}{l}{$\mathbf{C H}_{4}$} & $\mathbf{C O}$ & $\mathbf{H}_{2}$ & $\mathbf{O}_{2}$ \\
\cline { 2 - 5 } MnSA & $5.0^{\mathrm{a}}(0.8)^{\mathrm{b}}$ & $5.1(5.3)$ & $14.2(11.8)$ & $11.3(8.1)$ \\
MnGBHNE & $9.2(1.3)$ & $6.4(1.4)$ & $19.2(9.0)$ & $8.6(9.7)$ \\
MnGBMPB & $9.3(2.2)$ & $9.0(2.4)$ & $26.4(14.8)$ & $8.4(9.4)$ \\
MnBR & $12.7(1.7)$ & $8.2(3.0)$ & $20.5(12.5)$ & $8.5(9.9)$ \\
Mn ore $^{17}$ & $7.2^{\mathrm{c}}$ & - & $19.8^{\mathrm{c}}$ & - \\
SINAI-A $^{19}$ & 3.6 & - & 5.4 & - \\
GUIZHOU $^{19}$ & 0.9 & - & 1.3 & - \\
Ilmenite $^{34}$ & 5.0 & 2.5 & 7.9 & 9.7 \\
Bauxite waste $^{34}$ & 3.4 & 3.9 & 10.5 & 4.1 \\
Hematite $^{34}$ & 3.3 & 3.4 & 12.4 & 5.5 \\
\hline
\end{tabular}

${ }^{\mathrm{a}}$ calcined material ( ) $)^{\mathrm{b}}$ used materials; ${ }^{\mathrm{c}}$ averages between 900 and $1000^{\circ} \mathrm{C}$ 
Table 4 Minimum solids inventory ( $\mathrm{kg}$ solids per $\mathrm{MW}_{\text {th }}$ of fuel) required in fuel and air reactors to reach $100 \%$ combustion efficiency of $\mathrm{CH}_{4}, \mathrm{CO}, \mathrm{H}_{2}$ at $950^{\circ} \mathrm{C}$.

\begin{tabular}{llll}
\hline & \multicolumn{1}{l}{$\mathrm{CH}_{4}$} & $\mathbf{C O}$ & $\mathbf{H}_{2}$ \\
\cline { 2 - 4 } MnSA & $629^{\mathrm{a}}(54)^{\mathrm{b}}$ & $63(34)$ & $34(49)$ \\
MnGBHNE & $380(71)$ & $236(39)$ & $44(41)$ \\
MnGBMPB & $222(44)$ & $139(32)$ & $27(43)$ \\
MnBR & $289(55)$ & $112(38)$ & $32(40)$ \\
Ilmenite $^{39}$ & $167(42)$ & $105(30)$ & $42(35)$ \\
\hline
\end{tabular}

${ }^{\mathrm{a}}$ for fuel reactor; ()$^{\mathrm{b}}$ for air reactor 